\title{
Title: Individualized ctDNA Fingerprints to Monitor Treatment Response and Recurrence in Multiple Cancer Types
}

Authors: Jiaping $\mathrm{Li}^{1 *}$, Wei Jiang ${ }^{2 *}$, Jinwang Wei ${ }^{3 *}$, Jianwei Zhang ${ }^{4}$, Linbo Cai ${ }^{5}$, Minjie Luo ${ }^{6}$, Zhan Wang ${ }^{7}$, Wending Sun ${ }^{3}$, Chen Wang ${ }^{3}$, Chun Dai ${ }^{3}$, Guan Wang ${ }^{3}$, Qiang $\mathrm{Xu}^{3 \dagger}$ and Yanhong Deng $^{8 \dagger}$.

* These authors contributed equally to this work; †Corresponding authors.

\section{Affiliations:}

${ }^{1}$ Department of Interventional Oncology, The First Affiliated Hospital,Sun Yat-sen University, Guangdong, China;

${ }^{2}$ Department of Radiation Oncology, Huanhu Hospital, Tianjin, China;

${ }^{3}$ GenomiCare Biotechnology Co. Ltd, Shanghai, China;

${ }^{4}$ Department of Medical Oncology, The Sixth Affiliated Hospital of Sun Yat-sen University, Guangdong, China;

${ }^{5}$ Department of oncology Guang Dong Sanjiu Brain Hospita, Guangdong, China;

${ }^{6}$ Department of pediatric neurosurgery, ZhuJiang Hospital, Guangdong, China;

${ }^{7}$ Department of Medical Oncology, Changzheng Hospital, second Military Medical University, shanghai 200003, China

${ }^{8}$ Department of Medical Oncology, The Sixth Affiliated Hospital of Sun Yat-sen University, Guangdong, China.

*To whom correspondence should be addressed:

Qiang.Xu@genomicarebio.com

One Sentence Summary: ctDNA fingerprint panels were customized to predict the treatment response for multiple cancer types from individual whole-exome sequencing data.

Abstract: Circulating tumor DNA (ctDNA) panels hold high promise of accurately predicting the therapeutic response of tumors while being minimally invasive and cost-efficient. However, their use has been limited to a small number of tumor types and patients. Here, we developed individualized ctDNA fingerprints suitable for most patients with multiple cancer types. The panels were designed based on individual whole-exome sequencing data in 521 Chinese patients and targeting high clonal population clusters of somatic mutations. Together, these patients represent 12 types of cancers and seven different treatments. The customized ctDNA panels have a median somatic mutation number of 19 , most of which are patient-specific rather than cancer hotspot mutations; $66.8 \%$ of the patients were ctDNA-positive. We further evaluated the ctDNA content fraction (CCF) of the mutations, and analyzed the association 
between the change of ctDNA concentration and therapeutic response. We followed up 106 patients for clinical evaluation, demonstrating a significant correlation of changes in ctDNA with clinical outcomes, with a consistency rate of $93.4 \%$. In particular, the median CCF increased by $204.6 \%$ in patients with progressive disease, decreased by $82.5 \%$ in patients with remission, and was relatively stable in patients with stable disease. Overall, $85 \%$ of the patients with a ctDNApositive status experienced metastasis or relapse long before imaging detection, except for two patients who developed recurrence and metastasis almost simultaneously. The average lead time between the first ctDNA-positive finding and radiological diagnosis was 76 days in three patients that changed from a ctDNA-negative to -positive status. Our individualized ctDNA analysis can effectively monitor the treatment response, metastasis, and recurrence in multiple cancer types in patients with multiple treatment options, therefore offering great clinical applicability for improving personalized treatment in cancer.

\section{[Main Text:]}

\section{Introduction}

The incidence of cancer is increasing worldwide (1). Despite continuous development of new treatment strategies, the therapeutic effectiveness and recurrence remain difficult to monitor and it is hard to predict disease progress, which is essential for making appropriate clinical decisions. Although radiological imaging and protein biomarker analysis in the blood remain the most common methods of predicting treatment outcome in cancer, they both lack sensitivity and specificity $(2,3)$. Thus, new methods with high sensitivity and specificity are needed to monitor the treatment response in real-time and assist in the timely adjustment of a therapeutic regimen according to the most recent gene mutation status.

Circulating tumor DNA (ctDNA) has emerged as a new biomarker to assess therapeutic efficacy and detect recurrence. ctDNA is derived from apoptotic or necrotic tumor cells and resides in the blood, allowing for repeatable sampling in a simple and non-invasive manner. Importantly, analysis of ctDNA can provide snapshots of the tumor burden and genomic profile because ctDNA has a short half-life and is highly specific to the tumor from which it is derived (4). Indeed, several studies have demonstrated the value of ctDNA in monitoring the treatment response. In a study of 53 patients with metastatic colorectal cancer (CRC) who received standard first-line chemotherapy, the fold change of the ctDNA level was correlated with the tumor response exhibited by computed tomography (CT) imaging at 8-10 weeks post-treatment (5). In another study, the majority of 46 patients who were initially diagnosed as having nonmetastatic triple-negative breast cancer showed metastasis and recurrence after one cycle of neoadjuvant chemotherapy, and all of these metastatic patients were found to be ctDNA-positive (6). In an open phase I clinical trial of the combination of BRAF, EGFR, and MEK inhibitors, patients with the BRAF V600E mutation showed a greater change of ctDNA and a higher ratio of partial response (PR) and complete response (CR) to treatments than the patients with less of a change of ctDNA and showing stable disease (SD) or progressive disease (PD) status. Notably, there was no significant difference in the expression level of the common protein biomarker carcinoembryonic antigen (CEA) between these groups (7). Therefore, ctDNA appears to be 
superior to standard radiological and protein tumor markers in predicting the therapeutic response.

In contrast to generic panels containing only tumor hotspot mutations, a ctDNA panel can be tailored to the tumor genetic profile of individual patients. The TRAcking non-small cell lung cancer evolution through therapy (Rx) (TRACERx) study customized each patient's ctDNA panel based on clonal mutations, which included a median of 11 clonal and six subclonal singlenucleotide variants (SNVs) per patient (8). The TRACERx study demonstrated that the tumor volume correlated with the allele variation frequency of the average clonal SNVs, and that dynamic measurement of plasma ctDNA could predict and confirm tumor recurrence earlier than clinical CT imaging (8). In another study, a ctDNA panel with 9-24 founding mutations detected residual disease in five out of the six patients with breast cancer after adjuvant therapy; the failure in detecting residual disease for the last patient was attributed to an insufficient blood sample for ctDNA analysis (9). These studies highlighted the successful use of customized ctDNA panels in monitoring lung and breast cancers.

Here, we developed a new platform of individualized ctDNA panels designed based on whole-exome sequencing (WES) data of individual patients. We used SciClone tools (10) to calculate and select the top 20-40 somatic mutations within high clonal population clusters to custom individualized ctDNA panels, and the ctDNA content fraction (CCF) was estimated based on the proportion of these acellular tumor somatic mutant DNA fragments in total cell-free DNA. We also used a pre-designed ctDNA panel with eight hotspot cancer genes to monitor acquired resistance mutations for comparison. We applied the new platform to detect ctDNA in longitudinally collected plasma samples from 521 Chinese patients who represented more than 12 tumor types and had received seven types of treatments, and explored the ability of using ctDNA to predict the treatment response and recurrence.

\section{Results}

\section{Validation of the individualized ctDNA fingerprint assay in reference and tumor samples}

To determine the detection threshold and sensitivity of the individualized ctDNA assay, we performed more than 150 tests for each variant with a gradient of allelic frequencies in the range of $0-15 \%$. Ten nanograms of ctDNA was used for each test. The background ctDNA value in the wild-type reference samples was $0.065 \% \pm 0.062 \%$ (mean \pm standard deviation). We set the sum of the mean and standard deviation, $0.127 \%$, as the threshold, which represents the upper confidence level of background noise. The specificity of detecting an individual mutation in the wild-type samples was $80.3 \%$, and the sensitivities of reference samples with expected allele frequencies of $0.1 \%, 0.25 \%$, and $0.5 \%$ were $40.6 \%, 75.0 \%$, and $96.3 \%$, respectively. Mutations with a known frequency greater than $1 \%$ were all successfully detected (Supplementary Table S1). Since each allele has two copies, the threshold CCF for positive detection is twice the reference sample threshold at about $0.25 \%$.

In addition to the sensitivity of a single variant, we calculated the sensitivities of a panel containing five and 10 mutants at concentrations of $0.10 \%, 0.25 \%$, and $0.50 \%$ standard references, which were $44.4 \%$ and $46.0 \%, 97.6 \%$ and $99.8 \%$, and $99.99 \%$ and $100 \%$, respectively. The specificities of the five and 10 mutants in wild-type samples were $98.7 \%$ and 99.9\% respectively. Therefore, a panel with more tumor-specific SNVs shows higher sensitivity 
and specificity. Based on these results, patients with CCF values higher than $0.25 \%$ were considered to be ctDNA-positive, although CCF values were still recorded for those lower than $0.25 \%$.

\section{Patients and study design}

Among the 552 cancer patients recruited in this study, WES data were obtained from 521 patients who had case-matched tumor specimen and blood samples. Individualized ctDNA assays were designed for each patient based on WES data using a median of 26 pairs of primers, ranging from 7 to 39. After filtering out amplicons with low amplification efficiency and poor quality, the number of amplicons included in the individualized ctDNA fingerprint assays ranged from 4 to 33, with a median of 19. All patients underwent at least two independent ctDNA tests, with some patients undergoing more than three tests. In total, 1436 individualized ctDNA tests were performed on the 521 patients. Among them, 106 patients received follow-up clinical evaluations: 80 patients had one follow-up visit, 21 patients had two follow-up visits, and five patients had three or more follow-up visits. The flow of the study design is illustrated in Figure 1.

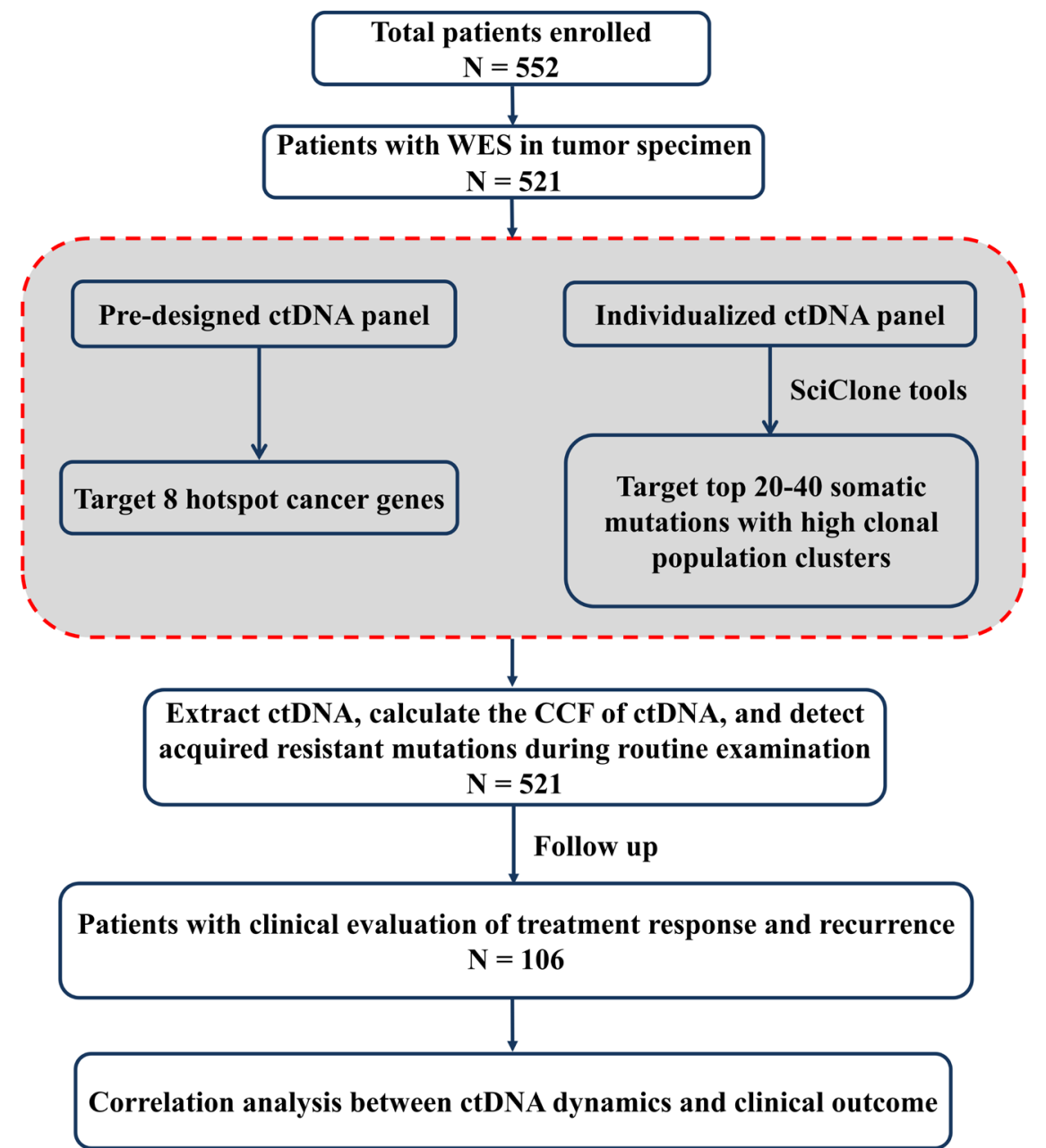


Fig. 1. Patient characterization and flow chart of the study design. The dotted red box shows the predesigned ctDNA panel and individualized ctDNA panel design.

\section{Application of individualized ctDNA fingerprint assays across multiple tumor types}

The distribution of tumor types across the 521 Chinese patients is shown in Figure 2A. The highest number of patients had colorectal cancer (CRC), followed by liver cancer, glioma [combined result of blood and cerebrospinal fluid (CSF) tests], and lung cancer in significant numbers; other cancer types included gastric cancer, cholangiocarcinoma, and pancreatic cancer. For the 15 patients with glioma, we additionally collected CSF along with the total 70 plasma samples. Overall, $66.8 \%$ of the patients were positive for ctDNA, and 50.9\%, 43.0\%, and 25.7\% of the patients had detectable ctDNA with a CCF above $0.5 \%, 1 \%$, and $5 \%$ respectively. In the glioma samples, ctDNA detection in the blood was significantly lower than that in the CSF $(24.3 \%$ vs. $80.0 \%, p<0.01$; Figure $2 \mathrm{~B})$, presumably due to blockage of the blood-brain barrier (BBB).

A

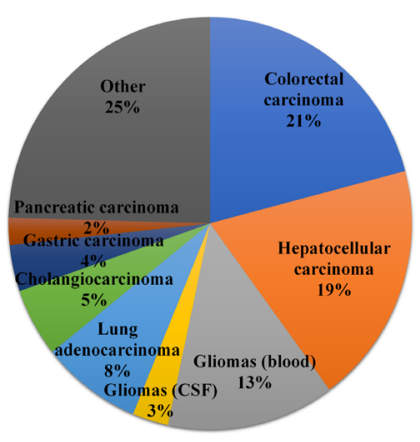

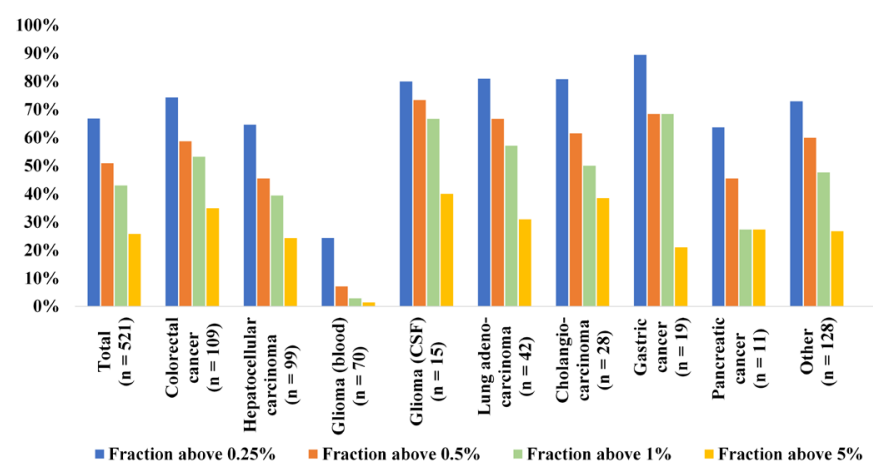

Fig. 2. Overview of ctDNA detection. (A) Distribution of tumor types in the 521 patients. (B) Fraction of patients with a ctDNA detection rate above $0.25 \%$ (blue), $0.5 \%$ (orange), $1 \%$ (light green), and $5 \%$ (yellow) in different cancer types.

We also tested for acquired drug-related mutations in 16 patients using a pre-designed ctDNA panel with eight hotspot cancer genes (BRAF, EGFR, ERBB2, KIT, KRAS, MET, NRAS, and PIK3CA). The majority of these patients had colon $(n=6)$ and lung $(n=3)$ cancers: all CRC patients acquired a KRAS mutation with a frequency $>0.05 \%$; two of the lung adenocarcinoma patients acquired the $E G F R$ p.T790M mutation, one with a frequency of $3.72 \%$ and the other $0.48 \%$; and PIK3CA, KIT, NRAS, and KRAS mutations were detected in patients with cholangiocarcinoma, hepatocellular carcinoma, gastrointestinal stromal and germ cell tumors, and breast, pancreatic, and head and neck cancers (Supplementary Table S2). 
We followed up 106 patients with regards to clinical outcomes. Among them, 26 patients had more than one clinical evaluation, which allowed us to assess the correlation between the changes in ctDNA levels and clinical evaluation at corresponding times. Of the $136 \mathrm{ctDNA}$ datasets, 127 (93.4\%) were consistent with the clinical evaluation. The consistency rates reached up to $100 \%$ for most of the major tumor types except for intracranial tumors at $71.4 \%(15 / 21)$ and pancreatic cancer at $60.0 \%(3 / 5)$.

For the consistent datasets, although the patients with lung cancer and urinary tract cancer received only two treatments, other patients experienced multiple treatments, including chemotherapy, radiotherapy, chemoradiotherapy, targeted therapy, immunotherapy, and combined chemotherapy and targeted therapy. In addition, some blood samples were taken from patients both just after surgery and during drug withdrawal, defined as postoperation and no treatment, respectively. Most of the surgical patients underwent tumor resection, whereas six received liver transplantation (Table 1). Among these different types of cancers and treatments, the change in ctDNA as determined by the individualized panel was consistent with clinical observations of PD, SD, and remission (Fig. 3A and B). As expected, the consistency rate in the peripheral blood samples was much lower than that in the CSF for glioma patients, at $66.7 \%$ and $100 \%$, respectively, reflecting the physical inhibition by the BBB. 
Table 1. Distribution of treatment types in different cancer types.

\begin{tabular}{|c|c|c|c|c|c|c|c|c|c|}
\hline & Postoperation & Chemotherapy & Radiotherapy & chemoradiotherapy & $\begin{array}{l}\text { Targeted } \\
\text { therapy }\end{array}$ & $\begin{array}{c}\text { Targeted } \\
\text { therapy }+ \\
\text { chemothe } \\
\text { rapy }\end{array}$ & Immunotherapy & $\begin{array}{l}\text { No } \\
\text { treatment }\end{array}$ & Total \\
\hline $\begin{array}{l}\text { Colorectal } \\
\text { carcinoma }\end{array}$ & 4 & 10 & 0 & 0 & 3 & 10 & 2 & 3 & 32 \\
\hline $\begin{array}{l}\text { Hepatocellular } \\
\text { carcinoma }\end{array}$ & 13 & 3 & 1 & 0 & 9 & 0 & 0 & 1 & 27 \\
\hline Intracranial tumor & 0 & 10 & 1 & 4 & 0 & 0 & 0 & 0 & 15 \\
\hline Cholangiocarcinoma & 1 & 3 & 0 & 0 & 3 & 1 & 3 & 1 & 12 \\
\hline Lung cancer & 0 & 0 & 0 & 0 & 9 & 0 & 1 & 0 & 10 \\
\hline Breast cancer & 0 & 1 & 0 & 1 & 2 & 2 & 0 & 0 & 6 \\
\hline Esophageal cancer & 0 & 0 & 1 & 0 & 1 & 1 & 2 & 0 & 5 \\
\hline Pancreatic cancer & 0 & 1 & 0 & 0 & 1 & 0 & 1 & 0 & 3 \\
\hline Gastric cancer & 0 & 1 & 1 & 0 & 0 & 0 & 1 & 0 & 3 \\
\hline Urinary tract cancer & 0 & 2 & 0 & 0 & 1 & 0 & 0 & 0 & 3 \\
\hline Soft tissue sarcoma & 0 & 1 & 0 & 0 & 1 & 1 & 0 & 0 & 3 \\
\hline Other & 0 & 3 & 1 & 1 & 3 & 0 & 0 & 0 & 8 \\
\hline Total & 18 & 35 & 5 & 6 & 33 & 15 & 10 & 5 & 127 \\
\hline
\end{tabular}




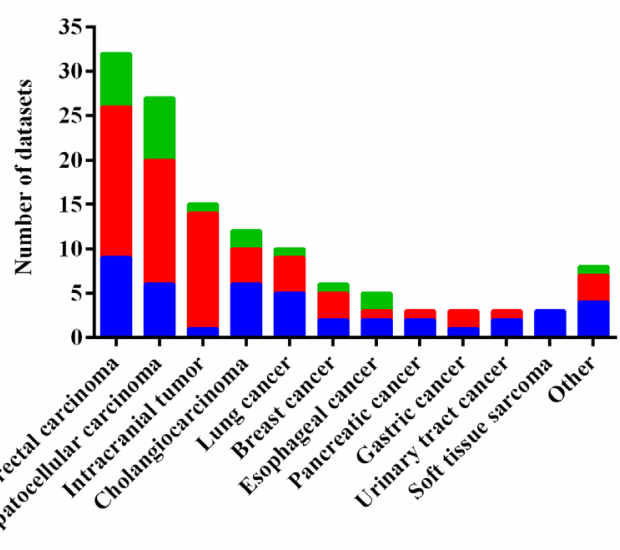

B

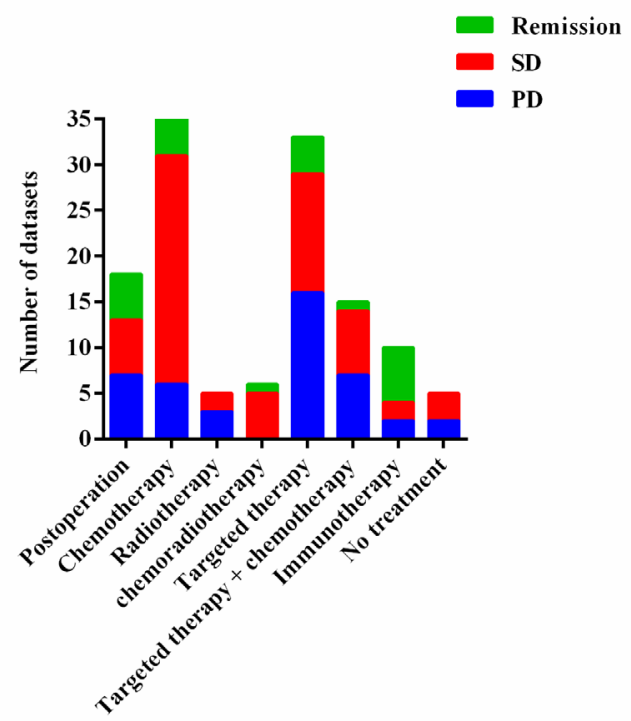

Fig. 3. Distribution of treatment responses [progression-free disease (PD), stable disease (SD), and remission] according to different tumor types (A) and treatments (B).

We then analyzed the corresponding ctDNA levels with clinical outcome metrics, including PD, SD, and remission. The median CCF of patients with PD was $2.21 \%$. There was no difference in the median CCF between SD patients and those who experienced remission, at $0.17 \%$ and $0.31 \%$, respectively $(\mathrm{p}=0.144)$. However, the CCF of the SD and remission patients was one order of magnitude lower than that of the PD patients, representing a statistically significant difference (both $\mathrm{p}<0.001$ ) (Fig. 4A).

We also analyzed the percentage change in ctDNA levels between different detection times along with the corresponding time of clinical evaluations. The CCF detected at the time of clinical evaluation significantly differed from the levels detected at the last assessment for the patients with PD and remission, but there was no such difference for the SD patients $(\mathrm{p}<0.0001$, $<0.0001$, and $\mathrm{p}=0.0520$, respectively; Wilcoxon signed-rank test). Overall, $67.2 \%$ of SD patients showed ctDNA levels below the threshold at two time points, which was considered as a change to 0 (Fig. 4B). However, there was high variability among PD patients, with a median change of $204.6 \%$ in ctDNA (Fig. 4B). The receiver operating characteristic (ROC) curve suggested that the cut-off value for predicting PD was a $15 \%$ increase in the ctDNA level (Fig. $4 C)$. The maximum change of ctDNA observed was a $\sim 29,000$-fold increase, which occurred in a patient with brain metastases of breast cancer (Fig. 4B). After surgical removal of the brain metastases, the patient's condition was relieved, and the ctDNA level substantially dropped down to $0.29 \%$. However, after 3 months, the ctDNA of this patient again increased to $84.4 \%$, which 
corresponded with new metastases to the pectoralis major muscle and the brain metastases also recurred.

Among the 43 PD patients, 23 showed metastasis and recurrence (Table 2). In addition to 10 patients who had metastases and relapses identified prior to the first ctDNA test, 13 patients were with metastasis and recurrence were followed-up. Eight patients were at or above the $0.25 \%$ threshold at the first ctDNA test, five patients showed a change in the CCF from below the threshold to above and reaching ctDNA-positive status. In summary, all patients with metastasis and recurrence showed a ctDNA-positive status, which could accurately predict metastasis and recurrence. Except for patients P1822 and P2022 who were tested to be ctDNApositive and underwent imaging metastasis and recurrence at almost the same time, $85 \%$ of the patients $(11 / 13)$ reached the ctDNA-positive status earlier than the imaging diagnosis. The lead time between the first detection of positivity for ctDNA and radiological metastasis or recurrence in patients P2829, P1782, and P1609 was 33, 68, and 128 days, respectively, with an average of 76 days. Moreover, $82.6 \%(19 / 23)$ of the patients had at least one test with a CCF above $1 \%$. Patient P3079 had a ctDNA concentration of $4.99 \%$ before the right hepatectomy, and the postoperative ctDNA concentration decreased by $80 \%$, but still considered to be ctDNA-positive, and then the patient experienced relapse after 2 months. 
A

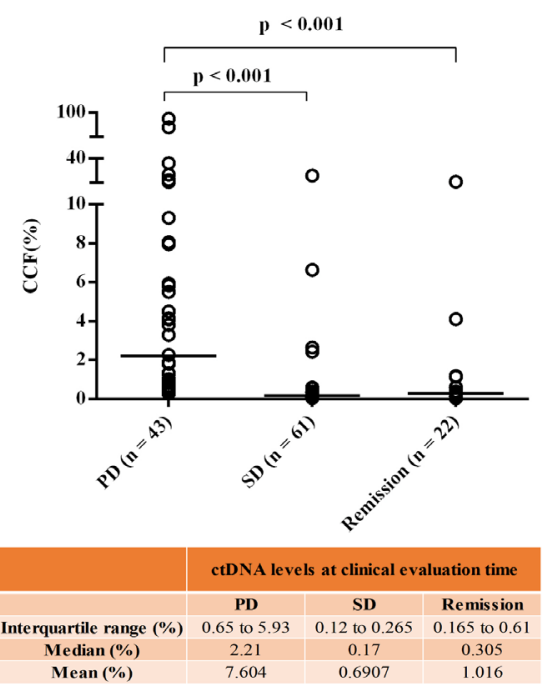

$\mathrm{B}$

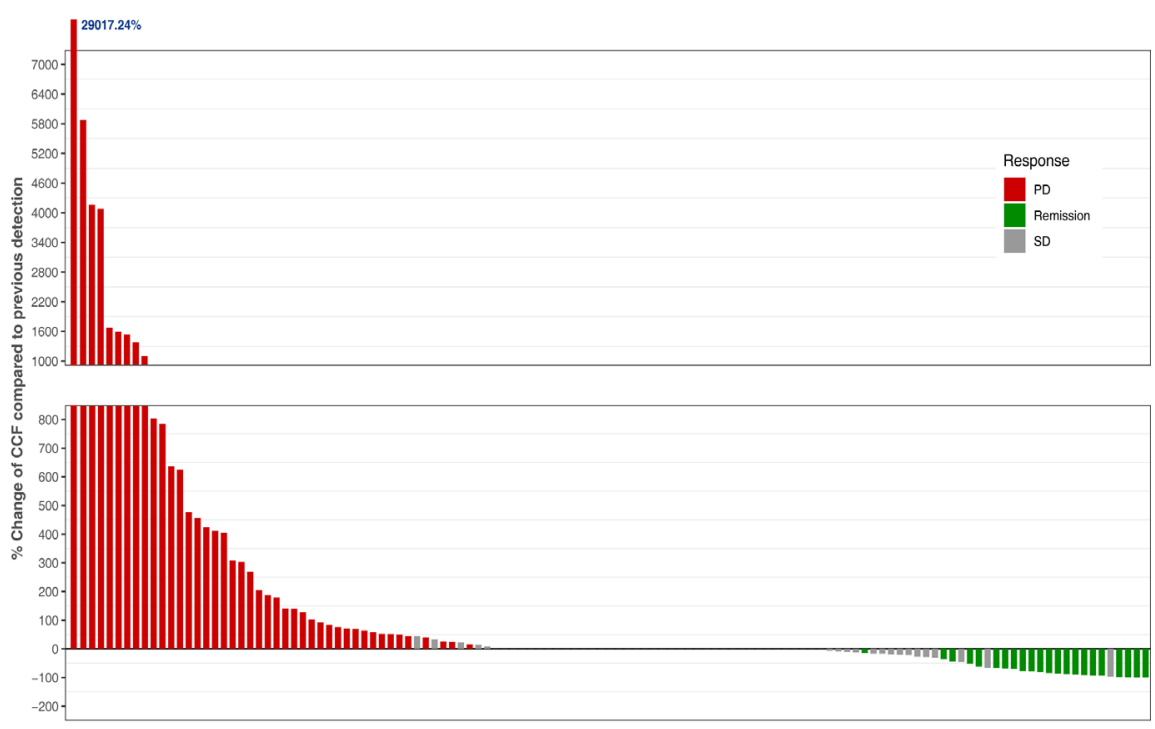

\begin{tabular}{|c|c|c|c|}
\hline & \multicolumn{3}{|c|}{ Changes of ctDNA corres ponding to clinical } \\
evaluation
\end{tabular}

$\mathrm{C}$

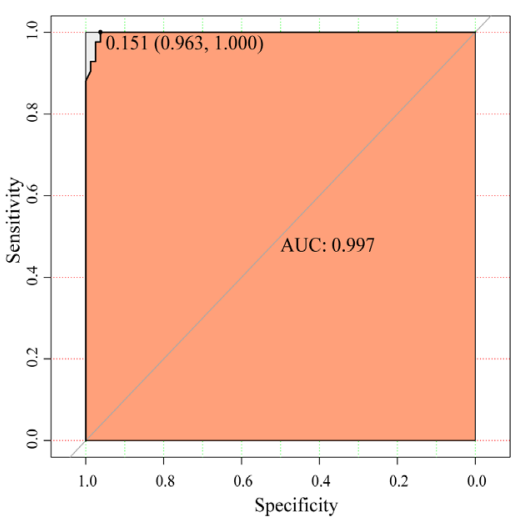


Fig. 4. ctDNA concentration change and its use for progression prediction. (A) Distribution of ctDNA concentration in different treatment responses. CCF values were significantly different between $\mathrm{PD}$ and $\mathrm{SD}$, and between PD and remission. The p-values were obtained from the Kruskal-Wallis $\mathrm{H}$ test. n, number of patients. (B) Change of ctDNA concentration after treatment corresponding to the clinical evaluation. (C) ROC analysis of the ctDNA concentration change. The analysis suggested a threshold value of $15.1 \%$ to predict $P D$. 
Table 2. Surveillance of metastasis and recurrence by the individualized ctDNA fingerprint assay.

\begin{tabular}{|c|c|c|c|c|c|c|c|c|c|c|}
\hline \multirow{2}{*}{$\begin{array}{c}\text { Patient } \\
\text { ID }\end{array}$} & \multirow{2}{*}{ Cancer Type } & \multirow[t]{2}{*}{ Metastasis/Recurrence } & \multirow{2}{*}{$\begin{array}{c}\text { ctDNA detection time corresponding } \\
\text { to metastasis/recurrence }\end{array}$} & \multicolumn{6}{|c|}{ CCF (\%) } & \multirow{2}{*}{ Trend } \\
\hline & & & & 1 st & 2nd & 3rd & 4th & 5th & 6th & \\
\hline P965 & Soft tissue sarcoma & Metastasis + recurrence & before $1 \mathrm{st}$ & 5.69 & 12.96 & 19.74 & & & & 18 \\
\hline P1273 & Lung adenocarcinoma & Metastasis & before $1 \mathrm{st}$ & 0.22 & 2.21 & 2.82 & 25.2 & 4.1 & 3.33 & \\
\hline P1472 & Liver cancer & Recurrence & $3 \mathrm{rd}$ & 0.25 & 0.22 & 0.6 & 3.7 & 0.4 & & \\
\hline P1550 & Cholangiocarcinoma & Recurrence & $3 \mathrm{rd}$ & 0.59 & 0.54 & 0.81 & & & & 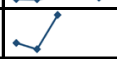 \\
\hline P1609 & Colorectal cancer & Metastasis & 4th & 0.23 & 0.2 & 0.29 & 1.22 & 0.23 & 0.36 & \\
\hline $\mathrm{P} 1670$ & Lung adenocarcinoma & Metastasis & before $1 \mathrm{st}$ & 0.57 & 34.09 & 62.89 & & & & 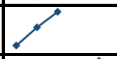 \\
\hline P1782 & Cholangiocarcinoma & Metastasis + recurrence & between 3rd and 4th & 0.09 & 1.31 & 2.22 & 5.25 & 6.87 & & ـ \\
\hline P1822 & Liver cancer & Metastasis + recurrence & $3 \mathrm{rd}$ & 0.1 & 0.06 & 2.26 & 22.75 & & & $1=$ \\
\hline P1889 & other & Metastasis & 2nd & 0.25 & 1.02 & & & & & 1 \\
\hline P1909 & Pancreatic cancer & Recurrence & before $1 \mathrm{st}$ & 5.87 & 0.47 & 7.95 & & & & $V$ \\
\hline P2004 & Kidney cancer & Metastasis & before $1 \mathrm{st}$ & 0.37 & 1.87 & 0.28 & 4.13 & & & \\
\hline P2022 & Liver cancer & Recurrence & 2nd & 0.05 & 1.39 & 20.89 & & & & - \\
\hline P2036 & Head and neck cancer & Metastasis & before 1st & 0.23 & 0.19 & 1.81 & & & & 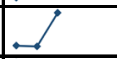 \\
\hline P2138 & Liver cancer & Metastasis & 3 rd & 1.56 & 0.61 & 0.83 & 0.6 & & & \\
\hline P2245 & Liver cancer & Recurrence & 3rd & 0.79 & 1.35 & 5.27 & 0.34 & 4.09 & & \\
\hline P2339 & Pancreatic cancer & Metastasis & $3 \mathrm{rd}$ & 0.43 & 0.54 & 0.58 & & & & 1 \\
\hline $\mathrm{P} 2565$ & Colorectal cancer & Metastasis & before $1 \mathrm{st}$ & 9.26 & 6.62 & 8.88 & & & & V \\
\hline $\mathrm{P} 2704$ & Breast cancer & Metastasis & before 1st & 1.02 & 0.32 & 0.28 & & & & Y \\
\hline P2829 & Colorectal cancer & Metastasis + recurrence & between 2nd and 3rd & 0.1 & 0.46 & 0.93 & & & & s. \\
\hline P2959 & Colorectal cancer & Metastasis + recurrence & before 1st & 1.32 & 3.8 & & & & & l \\
\hline P3028 & Liver cancer & Recurrence & $3 \mathrm{rd}$ & 0.48 & 0.27 & 0.65 & & & & $V$ \\
\hline P3079 & Liver cancer & Recurrence & between $2 \mathrm{nd}$ and $3 \mathrm{rd}$ & 4.99 & 1.14 & 5.83 & & & & $V$ \\
\hline P2745 & Breast cancer & Metastasis + recurrence & before 1st & 2.26 & 0.29 & 84.44 & & & & 1 \\
\hline
\end{tabular}


The clinical responses of nine patients were inconsistent with the dynamic changes of ctDNA. These included five patients with gliomas, two with pancreatic cancers, one with medulloblastoma, and one with breast cancer. Although all of the patients with glioma showed disease progression, their plasma ctDNA levels fluctuated below the threshold, owing to the low detection rate of ctDNA in plasma. This suggests that it is necessary to monitor ctDNA in the CSF, instead of the blood, for glioblastoma patients. A similar situation occurred in patients with pancreatic cancer, for whom disease progressed but the CCF was determined to be below the $0.25 \%$ threshold. The CCF values of the patient with medulloblastoma changed from $0.19 \%$ to $0.34 \%$ with an increase rate of $79 \%$. Although this change was close to that observed in PD patients, the status of this patient was SD. For breast cancer, the CCF of the first and second tests was $27.7 \%$ and $21.3 \%$, respectively. Although the CCF slightly reduced, the absolute value was still very high, which may reflect the PD status of this patient.

\section{Dynamics of individual mutations in the individualized ctDNA fingerprint assay}

We selected five patients who had at least three clinical evaluations, and analyzed their disease course in detail through tracking their radiological response and ctDNA dynamics, including the overall CCF and individual mutation changes detected in the personalized ctDNA panels. The five patients had lung adenocarcinoma, cholangiocarcinoma with liver transplant surgery, CRC, hepatocellular carcinoma, and breast cancer, respectively, and their changes in ctDNA were consistent with the clinical evaluations (Fig. 5). Patient A received gefitinib for more than one year, and then acquired the EGFR_p.E746_A750del and EGFR_p.T790M mutations. Before imaging confirmed PD in May of 2018, the fraction EGFR_p.T790M mutation slightly increased and then decreased, whereas the EGFR_p.E746_A750del mutation fraction increased continuously. After treatment with osimertinib, the patient achieved a CR and maintained low ctDNA levels. Moreover, the fluctuations in certain mutations observed in patient $\mathrm{D}$ and patient $\mathrm{E}$ differed from the overall trend of the panel. For patient $\mathrm{D}$, the ctDNA levels of DPYD and IGSF1 increased significantly in the second detection, and that of PCSK5 increased in the third test, but the overall ctDNA content of the panel decreased in the second and third detections. Patient E also contained an AP1M2 mutation that was distinct from the overall trend of ctDNA changes. 


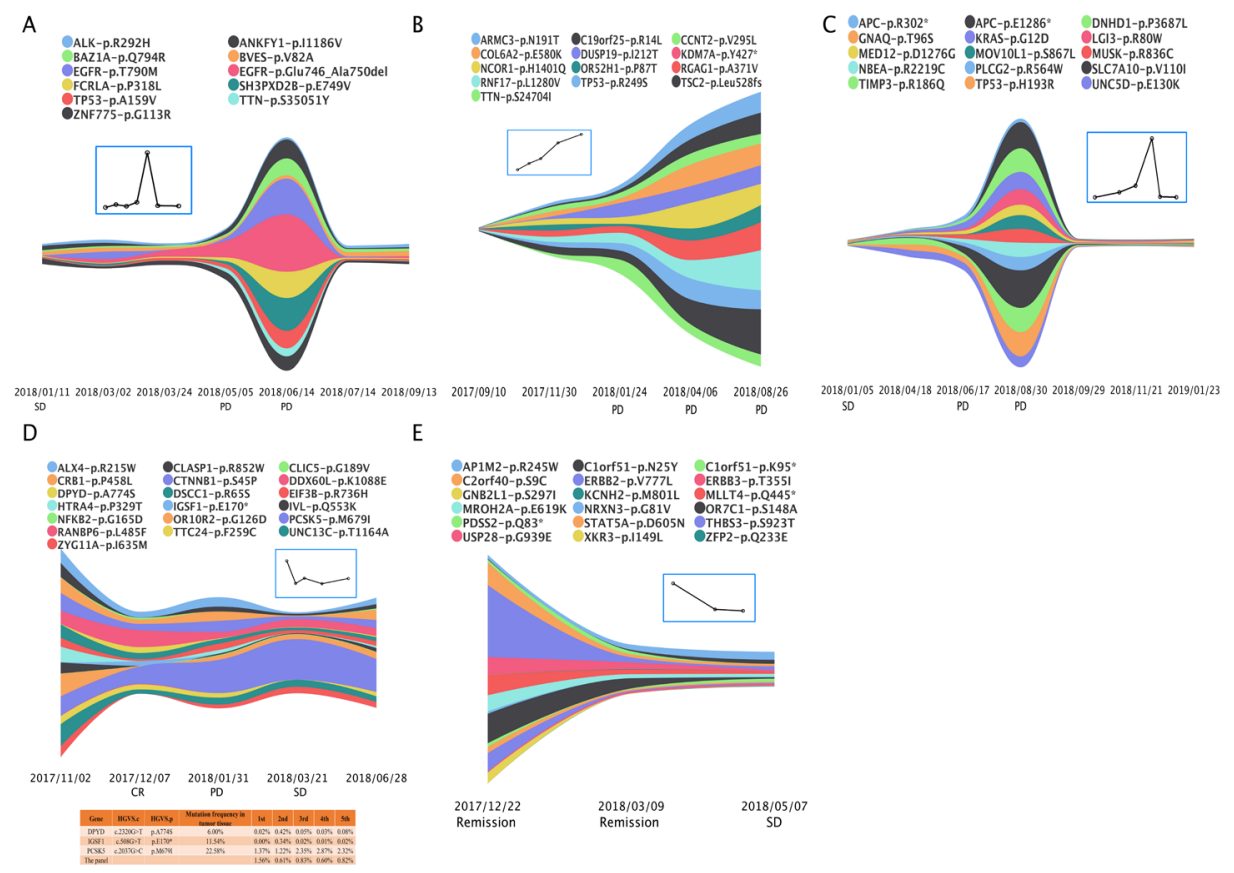

Fig. 5. Stream graph of five patients showing dynamics of individual mutations as well as the overall trend (inset line plot) as detected by ctDNA. The colors indicate different tumor genes and the specific mutations. (A) Lung adenocarcinoma; (B) cholangiocarcinoma with liver transplant surgery; (C) CRC; (D) hepatocellular carcinoma; and (E) breast cancer. For patient D, a table presents the dynamics of three mutations, which were inconsistent with the overall trend.

\section{Patient individualization of customized ctDNA panels}

We designed the individualized ctDNA panels based on the patients' own WES data, and analyzed the specificity of this individualization. A total of 144,158 mutations were detected in 521 patients by WES, including 99,490 mutations that were detected only once, accounting for $69.0 \%$ of all mutations. The 99,490 unique mutations were successfully incorporated in at least one individualized ctDNA panel, and $7762(84.9 \%)$ of the mutations were incorporated in only one panel; thus, these panels were highly specific to the individual patients.

To calculate the occurrence of common tumor-associated genes in the individualized ctDNA panel, we defined a tumor-associated gene set using the following method. Based on a previous survey including approximately 90 commercially available clinical gene panels developed by 40 different research institutes and companies, a list was generated containing 2054 genes (11). Using this list, we subsequently screened for 377 genes that occurred five or more times in all commercial panels (Supplementary Table S3). These genes were considered to be tumor-associated genes and potentially clinically actionable. Mutations with frequencies greater than 5\% were selected from the WES data and compared to these 377 genes; $114(21.8 \%)$ patients did not contain any of the 377 gene mutations on the list, and 365 (70\%) patients had 13 of these genes, while $42(8 \%)$ patients had more than three of the genes on the list. Similar results were obtained when comparing these 377 genes with the genes in the individualized ctDNA panels. 


\section{Discussion}

Although proof-of-concept studies have confirmed the clinical value of ctDNA to predict the treatment response (12), an expert panel from the American Society of Clinical Oncology and the College of American Pathologists concluded that most of the clinical validity and practicability of ctDNA testing reported to date are insufficient (13). Several challenges have to be overcome before ctDNA analysis can be translated to clinical application. Toward this end, we developed a strategy to design patient-specific ctDNA panels with high sensitivity and specificity, which can be applied to patients with multiple types of tumors that received several different treatments.

Our panels achieved a specificity of $99.99 \%$ when using 10 SNVs with a detection frequency above $0.25 \%$. The specificity was $99.93 \%$ in the reference samples. A median of 19 SNVs were detected in our ctDNA fingerprint assays. The ctDNA detection rate reached up to $67 \%$ in all patients, and about $80 \%$ in patients with CRC, non-small cell lung cancer (NSCLC), and gastric cancer. In comparison, a targeted deep-sequencing study of more than 70 tumorassociated genes in more than 20,000 patients with solid tumors showed a ctDNA detection rate of $85 \%$ overall, and $90 \%$ in patients with liver cancer, NSCLC, CRC, and gastric cancer (14). The higher detection rate in that study can be attributed to the fact that all of the included patients had been treated for late-stage cancers. This previous study also showed that the ctDNA detection rate was relatively low in brain cancer patients due to the $\mathrm{BBB}(14)$, which is consistent with our present findings.

Previous studies showed that ctDNA could indicate the treatment response and detect recurrence earlier than radiographic imaging in $\mathrm{CRC}$ patients that received surgery or chemotherapy (15-17). In a study of 20 patients with metastatic breast cancer, 95\% of the patients showed ctDNA fluctuations consistent with imaging-determined PD and SD using a patient-specific ctDNA panel, and $53 \%$ of the patients showed an increase in ctDNA that occurred earlier than the imaging-detected PD (18). Monitoring with a panel of 61 hotspot genes revealed that a ctDNA increase was associated with clinical relapse and PD in patients with muscle-invasive bladder cancer (19). These studies generally focused on only one type of cancer or one treatment. In contrast, in the present study, we collected data from patients with more than 12 tumor types and performed ctDNA monitoring on seven different treatment options, including liver transplantation. The ctDNA levels we detected in patients with PD, remission, and SD status were significantly different from each other. At the same time, the correlation between the changes of ctDNA level and clinical evaluation was high at $93 \%$.

Immunotherapy has shown great value in cancer treatment and has been approved by the Food and Drug Administration of the USA for the treatment of a variety of cancers $(20,21)$. Since it is expected to be applied to a large and growing number of patients, there is a large demand to develop effective methods for monitoring the efficacy of immunotherapy. Monitoring ctDNA changes is a promising approach to begin filling this gap. In a recent study in advanced NSCLC patients treated with nivolumab, $100 \%$ of the patients showing an objective response (OR) to immunotherapy had reduced ctDNA concentrations with a median change of $87.8 \%$, while $60 \%$ of the non-OR patients had increased ctDNA concentrations (22). In the present study, our individualized ctDNA panels successfully tracked PD, remission, and SD in patients with digestive tract cancers who received treatment with PD-L1 blockers and cell immunotherapy. The consistency rate reached up to $100 \%(10 / 10)$ between the trends of ctDNA 
and disease status change (Fig. 3). Thus, this method can effectively monitor multiple cancer types and treatment modes.

The ctDNA panels also have advantages over monitoring only single mutations in predicting disease development. The dynamics of a single mutation representation can be inconsistent with clinical assessments in such cases as well as the overall trend of multiple mutations. In a breast cancer patient whose status changed from SD to PD, the ctDNA content of most mutations increased, but the level of ZFYVE21, a known breast cancer marker, continued to decrease (18). Similarly, the NRAS level, a known melanoma marker, was reduced by 10 -fold in a melanoma patient, but the patient's disease nevertheless progressed (23). These reports are consistent with our findings (Fig. 5D-E). Hence, we monitored multiple patient-specific mutations to avoid this problem.

In addition to monitoring disease status, our ctDNA panels also have potential to predict patient prognosis at an earlier stage than currently possible. The ROC analysis identified a $15.1 \%$ increase in ctDNA as the optimal threshold for predicting PD. The corresponding AUC value was 0.997 , suggesting a high confidence level (Fig. 4C). Importantly, except for patients with recurrence or metastasis identified before the first ctDNA test, $85 \%$ of the patients $(11 / 13)$ with a ctDNA-positive status at the first ctDNA test or who converted to a ctDNA-positive status during follow-up experienced recurrence or metastasis far before these events were detected by imaging. The remaining patients tested as ctDNA-positive and demonstrated recurrence and metastasis by imaging at almost the same time. The average lead time from the first ctDNApositive finding to radioactive-confirmed metastasis and recurrence in three patients who reached a ctDNA-positive status during follow-up was 76 days. This finding is similar to a previous study in which 68 patients with advanced bladder cancer were followed-up and ctDNA monitoring showed a median lead time of 107 days (24). Given the relatively small sample size of this study, the clinical advantage of individualized ctDNA panels in predicting metastasis and recurrence need to be further explored on a larger scale in the future.

The cost of using individualized ctDNA panels is expected to be much lower than several previously reported ctDNA panels such as CAncer Personalized Profiling by deep Sequencing (CAPP-Seq), targeted error correction sequencing (TEC-Seq), and a commercially developed ctDNA test kit including more than 50 genes (25-28). All of these panels were designed to target tumor hotspot genes, which account for only a minority of the total ctDNA in the plasma. In cancer patients, somatic cell-free DNA (cfDNA) consists of variants derived from both clonal hematopoiesis and the tumor. Although the common tumor mutations also occur in the genome of white blood cells at high frequency, the majority of cfDNA variants are nevertheless derived from white cells produced in clonal hematopoiesis $(29,30)$. Therefore, detection based on common tumor mutations is of low efficiency and high cost.

In our present study, we used paired WES data from patients to select variants free of clonal hematopoietic cell interference. The resulting ctDNA panels customized for individual patients displayed high specificity for all patients; $85 \%$ of the selected mutations were detected only once, about $30 \%$ of the patients did not harbor common hotspot tumor genes, and the remaining $70 \%$ patients carried only $1-3$ hotspot genes. This detection efficiency was achieved by sequencing a total of about 30 patient-specific mutations per individual, and each of these mutations was harbored in a 100-bp amplicon. Thus, the overall sequencing and analysis involves only about $3-\mathrm{kb}$ sequences per individual. This greatly reduces the cost and time of analysis in comparison to those required for panels needing larger sequencing volumes (31). 
Nevertheless, the present individualized ctDNA fingerprints assay still has some limitations. Importantly, it requires prior WES analysis of the tumor tissue before ctDNA monitoring, which is impossible for some patients. Additionally, this assay only uses information of SNVs due to the short sequencing length and leaves out information about indels and longer range changes, including gene fusions/chromosomal rearrangements and copy number variations (CNVs), which are highly valuable diagnosis tools for some tumors $(32,33)$. Although the present platform mainly detects SNVs, there is relatively less information available on related fusions and CNVs. Furthermore, the present study was limited to patients with metastasis and recurrence, which requires further exploration of the full breadth of clinical benefits of these individualized ctDNA panels.

In conclusion, we developed a new ctDNA platform that could successfully monitor the treatment response, recurrence, and metastasis in a variety of cancer types and for patients receiving multiple treatments. Although further large-scale clinical trials are needed to confirm the utility of these individualized ctDNA panels in clinical settings, the panels offer the important advantages of convenience, accuracy, and efficiency, and show promise for improving personalized treatment decisions in a timely manner.

\section{Material and Methods}

\section{Patient samples}

Patients were recruited from 20 hospitals in China between May 2016 and December 2018. All patients provided written informed consent to use their genomic and clinical data for research purposes. All procedures involving human participation conformed to the ethical standards of the relevant institutions and/or National Research committees, as well as the 1964 Helsinki Declaration and its subsequent amendments or similar ethical standards.

Tumor tissues and blood samples of 552 Chinese patients diagnosed with cancer were collected. The percentage of tumor cells was assessed by pathologists, and only samples with a tumor content greater than $20 \%$ were included in this study. A series of plasma samples were collected at intervals set by the treating physicians. Treatment response and recurrence were evaluated by oncologists based on radiological imaging. ctDNA tests were conducted within the same month of radiological imaging for over $90 \%$ of the cases. In the remaining $10 \%$ of cases, the time between the ctDNA test and radiological imaging was between 1-2 months. All patients were followed up for a median of 6 months (range 1-16 months).

Reference samples used to evaluate the ctDNA detection threshold and performance were prepared from commercial references including Quantitative Multiplex Formalin Compromised (Mild) Reference Standard (cat\# HD798, Horizon Discovery, Cambridge, UK), 1\% Multiplex I cfDNA Reference Standard (cat\# HD778, Horizon Discovery, Cambridge, UK), and 100\% Wildtype (Tru-Q 0) (cat\# HD752, Horizon Discovery, Cambridge, UK). The reference standards were mixed in different proportions to make serial reference samples including different variants with a gradient allelic frequency of $15 \%, 10 \%, 6 \%, 3 \%, 1 \%, 0.5 \%, 0.25 \%$, and $0 \%$, respectively. Variant frequencies detected in ctDNA measurements were then used to calculate the sensitivity and specificity of the assay.

\section{DNA extraction}


For WES analysis, DNA was extracted from the tumor tissue and blood samples previously frozen using Maxwell ${ }^{\circledR}$ RSC Tissue DNA Kit (cat\# AS1610, Promega, Madison, WI, USA) and Maxwell ${ }^{\circledR}$ RSC Blood DNA Kit (cat\# AS1400, Promega, Madison, WI, USA) respectively. In addition to fresh tumor tissues, the samples included formalin-fixed, paraffinembedded (FFPE) tissues, which can damage the quality of DNA; therefore, we used NEBNext FFPE DNA Repair Mix (cat\# M6630, New England Biolabs, Ipswich, MA, USA) to reduce this damage. For the ctDNA assay, $10 \mathrm{ml}$ of whole blood was collected and transported using Streck's BCT tubes. cfDNA in the plasma and CSF was then extracted using MagMAX ${ }^{\mathrm{TM}}$ CellFree DNA Isolation Kit (cat\# 29319, ThermoFisher Scientific, Waltham, MA, USA) and stored at $-20^{\circ} \mathrm{C}$ until use.

\section{WES analysis}

The whole exons of the tumor tissue and matched white blood cells were sequenced. Library preparation was performed using SureSelect Human All Exon Kit v5 (cat\# 59909857EN, Agilent Technologies, Santa Clara, CA, USA), sequencing was performed on the Illumina Xten platform, and data analysis was carried out as described previously (34).

\section{ctDNA panels}

Given the limitations of multiplex PCR platforms for producing homopolymer-associated indel errors $(35,36)$, the individualized ctDNA panel was mainly designed to detect somatic SNVs in the peripheral blood. We calculated the clonal clusters for each somatic mutation obtained from WES using SciClone tools, which computationally determines the number and composition of genetic clones across one or multiple samples. The clonal clusters were calculated with the following parameters: tumor purity reviewed by pathologists, tumor copy number alterations (CNA), loss of heterozygosity $(\mathrm{LOH})$ ratio in somatic mutation regions, and somatic variant allele frequencies (VAF). Regions of CNA and LOH were inferred from WES data for each patient using VarScan v2.4.2 tools (37). We selected the top 20-40 somatic mutations within high clonal population clusters, which were applied to Ion AmpliSeq ${ }^{\mathrm{TM}}$ Designer for multiplex PCR and amplicon sequencing.

The pre-designed ctDNA panel contains tumor hotspot markers $B R A F, E G F R, E R B B 2$, $K I T, K R A S, M E T, N R A S$, and PIK3CA to monitor acquired resistance mutations. The information of specific genetic mutations is provided in Supplementary Table S4.

\section{Multiplex PCR and amplicon sequencing}

A total of 5-10 ng of cfDNA was used as the template in the multiplex PCR and amplified using KAPA2G Fast Multiplex Mix kit (cat\# KK5802, KapaBiosystems, Wilmington, MA, USA) for the individualized ctDNA panel and Ion AmpliSeq ${ }^{\mathrm{TM}}$ Library Kit 2.0 (cat\# 4475345, ThermoFisher Scientific, Waltham, MA, USA) for the pre-designed panel. Amplified products were ligated to barcoded adapters from Ion Xpress Barcode Adapters 1-16 Kit (cat\# 4471250, ThermoFisher Scientific), followed by NGS library amplification using KAPA HiFi HotStart ReadyMixPCR Kit (cat\# KK2602, KapaBiosystems) for pre-designed ctDNA panel and Ion AmpliSeq ${ }^{\mathrm{TM}}$ Library Kit for individualized ctDNA, respectively. All libraries were sequenced using Ion Torrent next-generation sequencing platforms (Ion S5 Systems, ThermoFisher Scientific).

\section{CCF estimation}


After sequencing, high-quality data were retained for analysis according to the following criteria: (1) more than 70\% of bases scoring Q20 and above; (2) more than $40 \%$ of reads mapped to the designed amplicons; (3) average coverage of amplicons higher than $18,000 \times ;(4)>80 \%$ amplicons with a coverage above $1000 \times$. The human reference genome hg19 (Feb.2009 GRCh37/hg19) was used for reads alignment with BWA -0.7.12 (38). Samtools-0.1.18 (39) and bedtools-2.17.0 (40) were used to manipulate alignments, and SNVs were called with VarScan v2.4.2 (37) using the mpileup2snp program. We estimated the ctDNA content fraction in patients

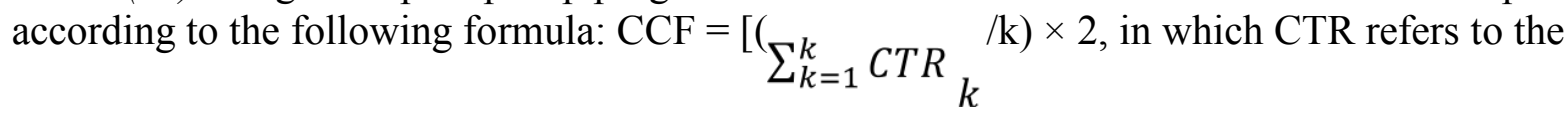
selected somatic mutation allele ratio in the ctDNA test, and $\mathrm{k}$ refers to the number of mutations. 


\section{Supplementary Materials}

Supplementary Table S1. Analytical performance and threshold of the multiplex PCR ctDNA assay for single mutation detection.

\begin{tabular}{|c|c|c|c|c|c|c|c|c|c|}
\hline $\begin{array}{c}\text { ctDNA concentration of } \\
\text { standard }\end{array}$ & $0 \%$ & $0.10 \%$ & $0.25 \%$ & $0.50 \%$ & $1 \%$ & $3 \%$ & $6 \%$ & $10 \%$ & $15 \%$ \\
\hline Number of replicates & 157 & 160 & 160 & 160 & 157 & 155 & 157 & 157 & 157 \\
\hline \multicolumn{10}{|l|}{$\begin{array}{l}\text { Observed allelic } \\
\text { frequency }\end{array}$} \\
\hline Mean & 0.06465 & 0.1221 & 0.2761 & 0.5774 & 1.132 & 3.38 & 6.358 & 9.858 & 15.26 \\
\hline Std. Deviation & 0.06247 & 0.1126 & 0.1679 & 0.2678 & 0.1966 & 0.4661 & 0.7514 & 0.9003 & 1.142 \\
\hline Std. Error of Mean & 0.004985 & 0.008899 & 0.01327 & 0.02117 & 0.01569 & 0.03744 & 0.05997 & 0.07186 & 0.09117 \\
\hline Lower $95 \% \mathrm{CI}$ of mean & 0.0548 & 0.1045 & 0.2499 & 0.5356 & 1.101 & 3.306 & 6.239 & 9.716 & 15.08 \\
\hline Upper $95 \%$ CI of mean & 0.0745 & 0.1397 & 0.3023 & 0.6192 & 1.163 & 3.454 & 6.476 & 10 & 15.44 \\
\hline Minimum & 0 & 0 & 0 & 0.02 & 0.66 & 2.1 & 4.74 & 7.66 & 11.69 \\
\hline 25\% Percentile & 0.01 & 0.03 & 0.1225 & 0.3725 & 1.01 & 3.05 & 5.8 & 9.29 & 14.31 \\
\hline Median & 0.05 & 0.07 & 0.285 & 0.555 & 1.11 & 3.41 & 6.31 & 9.76 & 15.26 \\
\hline $75 \%$ Percentile & 0.105 & 0.2075 & 0.4 & 0.76 & 1.255 & 3.67 & 6.95 & 10.38 & 15.93 \\
\hline
\end{tabular}




\begin{tabular}{|c|c|c|c|c|c|c|c|c|c|}
\hline Maximum & 0.23 & 0.41 & 0.76 & 1.43 & 1.77 & 4.94 & 8.2 & 14.43 & 18.49 \\
\hline Coefficient of variation & $96.62 \%$ & $92.17 \%$ & $60.81 \%$ & $46.39 \%$ & $17.37 \%$ & $13.79 \%$ & $11.82 \%$ & $9.13 \%$ & $7.49 \%$ \\
\hline $\begin{array}{c}\text { Sensitivity }(\%, \text { threshold } \\
=0.127 \%)\end{array}$ & NA & $40.62 \%$ & $75.00 \%$ & $96.25 \%$ & $100 \%$ & $100 \%$ & $100 \%$ & $100 \%$ & $100 \%$ \\
\hline
\end{tabular}

$\mathrm{NA}=$ not applicable 
Supplementary Table S2. Acquired drug-related mutations in 16 patients using a pre-designed ctDNA panel

\begin{tabular}{|c|c|c|c|}
\hline $\begin{array}{l}\text { Patient } \\
\text { ID }\end{array}$ & Tumor Type & New mutation & $\begin{array}{l}\text { Mutation } \\
\text { frequency }\end{array}$ \\
\hline $\operatorname{tdP} 1499$ & Colorectal cancer & $K R A S$ c. $183 \mathrm{~A}>\mathrm{C}$ p.Q $61 \mathrm{H}$ & $0.86 \%$ \\
\hline P2074 & Colorectal cancer & $K R A S$ c. $34 \mathrm{G}>\mathrm{T}$ p.G12C & $0.60 \%$ \\
\hline P2230 & Colorectal cancer & $K R A S$ c. $34 \mathrm{G}>\mathrm{T}$ p. $\mathrm{G} 12 \mathrm{C}$ & $0.43 \%$ \\
\hline P2800 & Colorectal cancer & $K R A S$ c. $38 \mathrm{G}>$ A p.G13D & $0.68 \%$ \\
\hline P2997 & Colorectal cancer & $K R A S$ c. $37 \mathrm{G}>\mathrm{T}$ p.. $\mathrm{G} 13 \mathrm{C}$ & $1.75 \%$ \\
\hline \multirow[t]{3}{*}{ P3439 } & Colorectal cancer & $K R A S$ c. $183 \mathrm{~A}>\mathrm{T}$ p.Q61H & $1.40 \%$ \\
\hline & & $N R A S$ c. $182 \mathrm{~A}>\mathrm{T}$ p.Q61L & $0.98 \%$ \\
\hline & & $\begin{array}{l}B R A F \text { c.G1780A } \\
\text { p.D594N }\end{array}$ & $0.69 \%$ \\
\hline P3489 & Lung adenocarcinoma & $\begin{array}{c}E G F R \text { c. } 2369 \mathrm{C}>\mathrm{T} \\
\text { p.T790M }\end{array}$ & $3.72 \%$ \\
\hline P0220 & Lung adenocarcinoma & $\begin{array}{c}E G F R \text { c. } 2369 \mathrm{C}>\mathrm{T} \\
\text { p.T790M }\end{array}$ & $0.48 \%$ \\
\hline P3260 & Lung adenocarcinoma & $\begin{array}{c}P I K 3 C A \text { c. } 1636 \mathrm{C}>\mathrm{A} \\
\text { p.Q546K }\end{array}$ & $2.41 \%$ \\
\hline P2842 & Breast cancer & $\begin{array}{c}P I K 3 C A \text { c.G1624A } \\
\text { p.E542K }\end{array}$ & $12.35 \%$ \\
\hline \multirow[t]{3}{*}{ P3416 } & Pancreatic cancer & $K R A S$ c. $35 \mathrm{G}>\mathrm{A}$ p.G12D & $3.46 \%$ \\
\hline & & $N R A S$ c. $181 \mathrm{C}>$ A p.. $\mathrm{Q} 61 \mathrm{~K}$ & $0.99 \%$ \\
\hline & & $N R A S$ c. $182 \mathrm{~A}>\mathrm{T}$ p.Q61L & $0.95 \%$ \\
\hline P3490 & Head and neck cancer & $\begin{array}{c}P I K 3 C A \text { c. } 3139 \mathrm{C}>\mathrm{T} \\
\text { p.H1047Y }\end{array}$ & $0.51 \%$ \\
\hline P3954 & $\begin{array}{c}\text { Gastrointestinal stromal } \\
\text { tumor }\end{array}$ & KIT c. $2467 \mathrm{~T}>$ A p.. $\mathrm{Y} 823 \mathrm{~N}$ & $2.56 \%$ \\
\hline P4789 & Cholangiocarcinoma & $\begin{array}{c}\text { PIK3CA c. } 1634 \mathrm{~A}>\mathrm{G} \\
\text { p.E545G }\end{array}$ & $0.82 \%$ \\
\hline P5513 & Germ cell tumor & KIT c. $2466 \mathrm{~T}>\mathrm{G}$ p.N822K & $3.81 \%$ \\
\hline P2393 & Hepatocellular carcinoma & $N R A S$ c. $35 \mathrm{G}>\mathrm{A}$ p.G12D & $0.32 \%$ \\
\hline
\end{tabular}


Supplementary Table S3. A total of 377 genes that occurred five times or more in a survey of 90 commercially available clinical gene panels developed by $\mathbf{4 0}$ different research institutes and companies .

\begin{tabular}{|c|c|c|c|}
\hline & gene_name & panel_count & gene_description \\
\hline 1 & KRAS & 39 & Kirsten rat sarcoma viral oncogene homolog \\
\hline 2 & TP53 & 39 & tumor protein $\mathrm{p} 53$ \\
\hline 3 & KIT & 38 & v-kit Hardy-Zuckerman 4 feline sarcoma viral oncogene homolog \\
\hline 4 & MET & 37 & MET proto-oncogene, receptor tyrosine kinase \\
\hline 5 & NRAS & 37 & neuroblastoma RAS viral (v-ras) oncogene homolog \\
\hline 6 & PTEN & 37 & phosphatase and tensin homolog \\
\hline 7 & RET & 37 & ret proto-oncogene \\
\hline 8 & PIK3CA & 36 & phosphatidylinositol-4,5-bisphosphate 3-kinase catalytic subunit alpha \\
\hline 9 & CDKN2A & 36 & cyclin-dependent kinase inhibitor $2 \mathrm{~A}$ \\
\hline 10 & ATM & 36 & ATM serine/threonine kinase \\
\hline 11 & BRAF & 36 & B-Raf proto-oncogene, serine/threonine kinase \\
\hline 12 & ALK & 35 & anaplastic lymphoma receptor tyrosine kinase \\
\hline 13 & $\mathrm{CDH} 1$ & 35 & cadherin 1 , type 1 \\
\hline 14 & AKT1 & 35 & v-akt murine thymoma viral oncogene homolog 1 \\
\hline 15 & $\mathrm{APC}$ & 34 & adenomatous polyposis coli \\
\hline 16 & MLH1 & 34 & mutL homolog 1 \\
\hline 17 & FLT3 & 34 & fms-related tyrosine kinase 3 \\
\hline 18 & ERBB2 & 34 & erb-b2 receptor tyrosine kinase 2 \\
\hline 19 & EGFR & 34 & epidermal growth factor receptor \\
\hline 20 & FGFR2 & 33 & fibroblast growth factor receptor 2 \\
\hline 21 & VHL & 33 & von Hippel-Lindau tumor suppressor, E3 ubiquitin protein ligase \\
\hline 22 & STK11 & 33 & serine/threonine kinase 11 \\
\hline 23 & PTPN11 & 33 & protein tyrosine phosphatase, non-receptor type 11 \\
\hline 24 & ABL1 & 33 & $\mathrm{ABL}$ proto-oncogene 1 , non-receptor tyrosine kinase \\
\hline 25 & SMAD4 & 32 & SMAD family member 4 \\
\hline 26 & PDGFRA & 32 & platelet-derived growth factor receptor, alpha polypeptide \\
\hline 27 & JAK2 & 32 & Janus kinase 2 \\
\hline 28 & FGFR1 & 32 & fibroblast growth factor receptor 1 \\
\hline 29 & KDR & 32 & kinase insert domain receptor \\
\hline 30 & HRAS & 32 & Harvey rat sarcoma viral oncogene homolog \\
\hline 31 & JAK3 & 31 & Janus kinase 3 \\
\hline 32 & $\mathrm{IDH} 2$ & 31 & isocitrate dehydrogenase $2(\mathrm{NADP}+)$, mitochondrial \\
\hline 33 & IDH1 & 31 & isocitrate dehydrogenase $1(\mathrm{NADP}+)$ \\
\hline 34 & FGFR3 & 31 & fibroblast growth factor receptor 3 \\
\hline
\end{tabular}




\begin{tabular}{|c|c|c|c|}
\hline 35 & NPM1 & 31 & nucleophosmin (nucleolar phosphoprotein B23, numatrin) \\
\hline 36 & RB1 & 31 & retinoblastoma 1 \\
\hline 37 & NOTCH1 & 31 & notch 1 \\
\hline 38 & CSF1R & 30 & colony stimulating factor 1 receptor \\
\hline 39 & GNAQ & 30 & guanine nucleotide binding protein (G protein), q polypeptide \\
\hline 40 & GNAS & 30 & GNAS complex locus \\
\hline 41 & $\mathrm{EZH} 2$ & 30 & enhancer of zeste 2 polycomb repressive complex 2 subunit \\
\hline 42 & SMO & 30 & smoothened, frizzled class receptor \\
\hline 43 & FBXW7 & 29 & F-box and WD repeat domain containing 7 \\
\hline 44 & MPL & 29 & MPL proto-oncogene, thrombopoietin receptor \\
\hline 45 & ERBB4 & 29 & erb-b2 receptor tyrosine kinase 4 \\
\hline 46 & CTNNB1 & 29 & catenin beta 1 \\
\hline 47 & GNA11 & 27 & guanine nucleotide binding protein ( $\mathrm{G}$ protein), alpha 11 (Gq class) \\
\hline 48 & $\mathrm{SRC}$ & 26 & SRC proto-oncogene, non-receptor tyrosine kinase \\
\hline 49 & SMARCB1 & 26 & $\begin{array}{l}\text { SWI/SNF related, matrix associated, actin dependent regulator of } \\
\text { chromatin, subfamily b, member } 1\end{array}$ \\
\hline 50 & CDK4 & 25 & cyclin-dependent kinase 4 \\
\hline 51 & HNF1A & 25 & HNF1 homeobox A \\
\hline 52 & BRCA2 & 23 & breast cancer 2 \\
\hline 53 & NF1 & 22 & neurofibromin 1 \\
\hline 54 & MAP2K1 & 22 & mitogen-activated protein kinase kinase 1 \\
\hline 55 & BRCA1 & 22 & breast cancer 1 \\
\hline 56 & WT1 & 22 & Wilms tumor 1 \\
\hline 57 & MSH2 & 21 & mutS homolog 2 \\
\hline 58 & MYC & 21 & v-myc avian myelocytomatosis viral oncogene homolog \\
\hline 59 & ROS1 & 21 & ROS proto-oncogene 1 , receptor tyrosine kinase \\
\hline 60 & PTCH1 & 20 & patched 1 \\
\hline 61 & MSH6 & 20 & mutS homolog 6 \\
\hline 62 & CCND1 & 19 & cyclin D1 \\
\hline 63 & NTRK1 & 18 & neurotrophic tyrosine kinase, receptor, type 1 \\
\hline 64 & PMS2 & 18 & PMS1 homolog 2, mismatch repair system component \\
\hline 65 & DNMT3A & 18 & DNA (cytosine-5-)-methyltransferase 3 alpha \\
\hline 66 & $\mathrm{TSC} 1$ & 18 & tuberous sclerosis 1 \\
\hline 67 & RUNX1 & 18 & runt-related transcription factor 1 \\
\hline 68 & CBL & 18 & $\mathrm{Cb} 1$ proto-oncogene, E3 ubiquitin protein ligase \\
\hline 164 & GATA2 & 18 & GATA binding protein 2 \\
\hline 69 & TET2 & 17 & tet methylcytosine dioxygenase 2 \\
\hline 70 & DDR2 & 17 & discoidin domain receptor tyrosine kinase 2 \\
\hline 71 & PALB2 & 17 & partner and localizer of BRCA2 \\
\hline 72 & ESR1 & 17 & estrogen receptor 1 \\
\hline 73 & TSC2 & 17 & tuberous sclerosis 2 \\
\hline
\end{tabular}




\begin{tabular}{|c|c|c|c|}
\hline 74 & ASXL1 & 17 & additional sex combs like 1 , transcriptional regulator \\
\hline 75 & CEBPA & 17 & CCAAT/enhancer binding protein (C/EBP), alpha \\
\hline 165 & CHEK2 & 17 & checkpoint kinase 2 \\
\hline 166 & BRIP1 & 17 & BRCA1 interacting protein C-terminal helicase 1 \\
\hline 167 & MUTYH & 17 & mutY DNA glycosylase \\
\hline 76 & PDGFRB & 16 & platelet-derived growth factor receptor, beta polypeptide \\
\hline 77 & CDK6 & 16 & cyclin-dependent kinase 6 \\
\hline 78 & SF3B1 & 16 & splicing factor $3 \mathrm{~b}$, subunit $1,155 \mathrm{kDa}$ \\
\hline 79 & ERBB3 & 16 & erb-b2 receptor tyrosine kinase 3 \\
\hline 80 & AR & 16 & androgen receptor \\
\hline 81 & MTOR & 16 & mechanistic target of rapamycin (serine/threonine kinase) \\
\hline 206 & KMT2A & 16 & lysine $(\mathrm{K})$-specific methyltransferase $2 \mathrm{~A}$ \\
\hline 82 & BAP1 & 15 & BRCA1 associated protein 1 \\
\hline 83 & BCL2 & 15 & B-cell CLL/lymphoma 2 \\
\hline 84 & AKT2 & 15 & v-akt murine thymoma viral oncogene homolog 2 \\
\hline 85 & GATA1 & 15 & GATA binding protein 1 (globin transcription factor 1) \\
\hline 86 & CCNE1 & 15 & cyclin E1 \\
\hline 87 & MAP2K2 & 15 & mitogen-activated protein kinase kinase 2 \\
\hline 88 & PIK3R1 & 15 & phosphoinositide-3-kinase regulatory subunit 1 \\
\hline 89 & ETV6 & 15 & ets variant 6 \\
\hline 90 & IKZF1 & 15 & IKAROS family zinc finger 1 \\
\hline 91 & MYCN & 14 & $\begin{array}{c}\text { v-myc avian myelocytomatosis viral oncogene neuroblastoma derived } \\
\text { homolog }\end{array}$ \\
\hline 92 & JAK1 & 14 & Janus kinase 1 \\
\hline 93 & FGFR4 & 14 & fibroblast growth factor receptor 4 \\
\hline 94 & MYD88 & 14 & myeloid differentiation primary response 88 \\
\hline 95 & MEN1 & 14 & menin 1 \\
\hline 96 & AURKA & 14 & aurora kinase A \\
\hline 97 & RAF1 & 14 & Raf-1 proto-oncogene, serine/threonine kinase \\
\hline 168 & PAX5 & 14 & paired box 5 \\
\hline 169 & KDM6A & 14 & lysine (K)-specific demethylase 6A \\
\hline 98 & NTRK3 & 13 & neurotrophic tyrosine kinase, receptor, type 3 \\
\hline 99 & NF2 & 13 & neurofibromin 2 (merlin) \\
\hline 100 & ATRX & 13 & alpha thalassemia/mental retardation syndrome X-linked \\
\hline 101 & TERT & 13 & telomerase reverse transcriptase \\
\hline 170 & NBN & 13 & nibrin \\
\hline 171 & SDHB & 13 & succinate dehydrogenase complex subunit B, iron sulfur (Ip) \\
\hline 172 & CREBBP & 13 & CREB binding protein \\
\hline 173 & U2AF1 & 13 & U2 small nuclear RNA auxiliary factor 1 \\
\hline 174 & GATA3 & 13 & GATA binding protein 3 \\
\hline 175 & SUFU & 13 & suppressor of fused homolog (Drosophila) \\
\hline
\end{tabular}




\begin{tabular}{|c|c|c|c|}
\hline 207 & BCL6 & 13 & B-cell CLL/lymphoma 6 \\
\hline 102 & IGF1R & 12 & insulin like growth factor 1 receptor \\
\hline 103 & AKT3 & 12 & v-akt murine thymoma viral oncogene homolog 3 \\
\hline 104 & NOTCH2 & 12 & notch 2 \\
\hline 105 & MDM2 & 12 & MDM2 proto-oncogene, E3 ubiquitin protein ligase \\
\hline 176 & FLCN & 12 & folliculin \\
\hline 177 & SDHD & 12 & succinate dehydrogenase complex subunit $\mathrm{D}$, integral membrane protein \\
\hline 178 & BMPR1A & 12 & bone morphogenetic protein receptor type IA \\
\hline 179 & FH & 12 & fumarate hydratase \\
\hline 180 & EP300 & 12 & E1A binding protein $\mathrm{p} 300$ \\
\hline 106 & MYCL & 11 & $\begin{array}{c}\text { v-myc avian myelocytomatosis viral oncogene lung carcinoma derived } \\
\text { homolog }\end{array}$ \\
\hline 107 & FOXL2 & 11 & forkhead box L2 \\
\hline 108 & RARA & 11 & retinoic acid receptor, alpha \\
\hline 109 & FLT4 & 11 & fms-related tyrosine kinase 4 \\
\hline 110 & FLT1 & 11 & fms-related tyrosine kinase 1 \\
\hline 111 & FANCA & 11 & Fanconi anemia complementation group A \\
\hline 112 & SMARCA4 & 11 & $\begin{array}{c}\text { SWI/SNF related, matrix associated, actin dependent regulator of } \\
\text { chromatin, subfamily a, member } 4\end{array}$ \\
\hline 113 & AXL & 11 & AXL receptor tyrosine kinase \\
\hline 114 & ARID1A & 11 & AT-rich interaction domain $1 \mathrm{~A}$ \\
\hline 115 & STAG2 & 11 & stromal antigen 2 \\
\hline 181 & PRKAR1A & 11 & protein kinase, cAMP-dependent, regulatory subunit type I alpha \\
\hline 182 & SDHC & 11 & $\begin{array}{l}\text { succinate dehydrogenase complex, subunit } \mathrm{C} \text {, integral membrane protein, } \\
\qquad 15 \mathrm{kDa}\end{array}$ \\
\hline 183 & EPCAM & 11 & epithelial cell adhesion molecule \\
\hline 184 & IL7R & 11 & interleukin 7 receptor \\
\hline 185 & CDKN2B & 11 & cyclin-dependent kinase inhibitor 2B (p15, inhibits CDK4) \\
\hline 186 & FANCC & 11 & Fanconi anemia complementation group $\mathrm{C}$ \\
\hline 187 & BLM & 11 & Bloom syndrome, RecQ helicase-like \\
\hline 188 & RAD51C & 11 & RAD51 paralog C \\
\hline 208 & SRSF2 & 11 & serine/arginine-rich splicing factor 2 \\
\hline 209 & BCOR & 11 & BCL6 corepressor \\
\hline 210 & ERCC2 & 11 & excision repair cross-complementation group 2 \\
\hline 211 & $\mathrm{CIC}$ & 11 & capicua transcriptional repressor \\
\hline 116 & BTK & 10 & Bruton agammaglobulinemia tyrosine kinase \\
\hline 117 & MRE11A & 10 & MRE11 homolog A, double strand break repair nuclease \\
\hline 118 & ETV1 & 10 & ets variant 1 \\
\hline 119 & PIK3R2 & 10 & phosphoinositide-3-kinase regulatory subunit 2 \\
\hline 189 & TOP1 & 10 & topoisomerase (DNA) I \\
\hline 190 & PHOX2B & 10 & paired-like homeobox $2 \mathrm{~b}$ \\
\hline 191 & TGFBR2 & 10 & transforming growth factor beta receptor II \\
\hline
\end{tabular}




\begin{tabular}{|c|c|c|c|}
\hline 192 & CDC73 & 10 & cell division cycle 73 \\
\hline 193 & PBRM1 & 10 & polybromo 1 \\
\hline 194 & NFE2L2 & 10 & nuclear factor, erythroid 2 like 2 \\
\hline 195 & MAP2K4 & 10 & mitogen-activated protein kinase kinase 4 \\
\hline 196 & DICER1 & 10 & dicer 1 , ribonuclease type III \\
\hline 212 & SETBP1 & 10 & SET binding protein 1 \\
\hline 213 & ZRSR2 & 10 & zinc finger (CCCH type), RNA binding motif and serine/arginine rich 2 \\
\hline 214 & PHF6 & 10 & PHD finger protein 6 \\
\hline 120 & CSF3R & 9 & colony stimulating factor 3 receptor \\
\hline 121 & ERG & 9 & v-ets avian erythroblastosis virus E26 oncogene homolog \\
\hline 122 & MCL1 & 9 & myeloid cell leukemia 1 \\
\hline 123 & MAPK1 & 9 & mitogen-activated protein kinase 1 \\
\hline 124 & CARD11 & 9 & caspase recruitment domain family member 11 \\
\hline 125 & PARP1 & 9 & poly(ADP-ribose) polymerase 1 \\
\hline 126 & CCND2 & 9 & cyclin D2 \\
\hline 127 & MDM4 & 9 & MDM4, p53 regulator \\
\hline 215 & BCR & 9 & breakpoint cluster region \\
\hline 216 & SDHA & 9 & succinate dehydrogenase complex subunit A, flavoprotein (Fp) \\
\hline 217 & CDK12 & 9 & cyclin-dependent kinase 12 \\
\hline 218 & BARD1 & 9 & BRCA1 associated RING domain 1 \\
\hline 219 & FANCG & 9 & Fanconi anemia complementation group $\mathrm{G}$ \\
\hline 220 & TSHR & 9 & thyroid stimulating hormone receptor \\
\hline 221 & SETD2 & 9 & SET domain containing 2 \\
\hline 222 & DAXX & 9 & death-domain associated protein \\
\hline 223 & TNFAIP3 & 9 & TNF alpha induced protein 3 \\
\hline 224 & PPP2R1A & 9 & protein phosphatase 2 regulatory subunit $\mathrm{A}$, alpha \\
\hline 225 & NKX2-1 & 9 & NK2 homeobox 1 \\
\hline 226 & MITF & 9 & microphthalmia-associated transcription factor \\
\hline 227 & FANCD2 & 9 & Fanconi anemia complementation group D2 \\
\hline 228 & RAD50 & 9 & RAD50 homolog, double strand break repair protein \\
\hline 229 & ERCC1 & 9 & excision repair cross-complementation group 1 \\
\hline 278 & ERCC5 & 9 & excision repair cross-complementation group 5 \\
\hline 279 & KMT2D & 9 & lysine $(\mathrm{K})$-specific methyltransferase $2 \mathrm{D}$ \\
\hline 128 & CHEK1 & 8 & checkpoint kinase 1 \\
\hline 129 & AURKB & 8 & aurora kinase B \\
\hline 130 & $\mathrm{CD} 274$ & 8 & CD274 molecule \\
\hline 131 & ETV4 & 8 & ets variant 4 \\
\hline 230 & $\mathrm{XPC}$ & 8 & xeroderma pigmentosum, complementation group $\mathrm{C}$ \\
\hline 231 & SMAD2 & 8 & SMAD family member 2 \\
\hline 232 & FANCF & 8 & Fanconi anemia complementation group $\mathrm{F}$ \\
\hline 233 & CDK8 & 8 & cyclin-dependent kinase 8 \\
\hline
\end{tabular}




\begin{tabular}{|c|c|c|c|}
\hline 234 & SYK & 8 & spleen tyrosine kinase \\
\hline 235 & CYLD & 8 & cylindromatosis (turban tumor syndrome) \\
\hline 236 & JUN & 8 & jun proto-oncogene \\
\hline 237 & PRDM1 & 8 & PR domain containing 1 , with ZNF domain \\
\hline 238 & TNFRSF14 & 8 & tumor necrosis factor receptor superfamily, member 14 \\
\hline 239 & SDHAF2 & 8 & succinate dehydrogenase complex assembly factor 2 \\
\hline 240 & BCL2L1 & 8 & BCL2-like 1 \\
\hline 280 & FAS & 8 & Fas cell surface death receptor \\
\hline 281 & TCF3 & 8 & transcription factor 3 \\
\hline 282 & RAC1 & 8 & $\begin{array}{l}\text { ras-related C3 botulinum toxin substrate } 1 \text { (rho family, small GTP binding } \\
\text { protein Rac1) }\end{array}$ \\
\hline 283 & FOXO1 & 8 & forkhead box $\mathrm{O} 1$ \\
\hline 284 & BIRC3 & 8 & baculoviral IAP repeat containing 3 \\
\hline 285 & RAD51D & 8 & RAD51 paralog D \\
\hline 286 & RRM1 & 8 & ribonucleotide reductase $\mathrm{M} 1$ \\
\hline 287 & ERCC3 & 8 & excision repair cross-complementation group 3 \\
\hline 288 & ERCC4 & 8 & excision repair cross-complementation group 4 \\
\hline 132 & DPYD & 7 & dihydropyrimidine dehydrogenase \\
\hline 133 & RICTOR & 7 & RPTOR independent companion of MTOR, complex 2 \\
\hline 134 & MED12 & 7 & mediator complex subunit 12 \\
\hline 135 & NTRK2 & 7 & neurotrophic tyrosine kinase, receptor, type 2 \\
\hline 136 & PPARG & 7 & peroxisome proliferator-activated receptor gamma \\
\hline 137 & ATR & 7 & ATR serine/threonine kinase \\
\hline 138 & ARAF & 7 & A-Raf proto-oncogene, serine/threonine kinase \\
\hline 139 & PDCD1 & 7 & programmed cell death 1 \\
\hline 199 & KMT2C & 7 & lysine $(\mathrm{K})$-specific methyltransferase $2 \mathrm{C}$ \\
\hline 200 & POLE & 7 & polymerase (DNA directed), epsilon, catalytic subunit \\
\hline 241 & XPO1 & 7 & exportin 1 \\
\hline 242 & ARID2 & 7 & AT-rich interaction domain 2 \\
\hline 243 & CDKN2C & 7 & cyclin-dependent kinase inhibitor $2 \mathrm{C}$ (p18, inhibits CDK4) \\
\hline 244 & FANCE & 7 & Fanconi anemia complementation group $\mathrm{E}$ \\
\hline 245 & NSD1 & 7 & nuclear receptor binding SET domain protein 1 \\
\hline 246 & KEAP1 & 7 & kelch like ECH associated protein 1 \\
\hline 247 & MYB & 7 & v-myb avian myeloblastosis viral oncogene homolog \\
\hline 248 & EPHA3 & 7 & EPH receptor A3 \\
\hline 249 & IRF4 & 7 & interferon regulatory factor 4 \\
\hline 250 & ABL2 & 7 & ABL proto-oncogene 2 , non-receptor tyrosine kinase \\
\hline 289 & PIK3CB & 7 & phosphatidylinositol-4,5-bisphosphate 3-kinase catalytic subunit beta \\
\hline 290 & PIK3CG & 7 & phosphatidylinositol-4,5-bisphosphate 3-kinase catalytic subunit gamma \\
\hline 291 & CBLB & 7 & Cbl proto-oncogene $\mathrm{B}, \mathrm{E} 3$ ubiquitin protein ligase \\
\hline 292 & CALR & 7 & calreticulin \\
\hline
\end{tabular}




\begin{tabular}{|c|c|c|c|}
\hline 293 & MAX & 7 & MYC associated factor $\mathrm{X}$ \\
\hline 294 & CD79B & 7 & CD79b molecule \\
\hline 295 & SOCS1 & 7 & suppressor of cytokine signaling 1 \\
\hline 296 & BUB1B & 7 & BUB1B, mitotic checkpoint serine/threonine kinase \\
\hline 297 & DDB2 & 7 & damage-specific DNA binding protein 2 \\
\hline 298 & LMO1 & 7 & LIM domain only 1 \\
\hline 299 & RUNX1T1 & 7 & runt-related transcription factor 1 ; translocated to, 1 (cyclin D-related) \\
\hline 300 & AMER1 & 7 & APC membrane recruitment protein 1 \\
\hline 301 & TFE3 & 7 & transcription factor binding to IGHM enhancer 3 \\
\hline 302 & PTPRD & 7 & protein tyrosine phosphatase, receptor type, D \\
\hline 303 & PIM1 & 7 & Pim-1 proto-oncogene, serine/threonine kinase \\
\hline 304 & EXT2 & 7 & exostosin glycosyltransferase 2 \\
\hline 305 & EXT1 & 7 & exostosin glycosyltransferase 1 \\
\hline 306 & CRLF2 & 7 & cytokine receptor-like factor 2 \\
\hline 307 & KDM5C & 7 & lysine $(\mathrm{K})$-specific demethylase $5 \mathrm{C}$ \\
\hline 140 & RHOA & 6 & ras homolog family member $\mathrm{A}$ \\
\hline 141 & TYMS & 6 & thymidylate synthetase \\
\hline 142 & CRKL & 6 & v-crk avian sarcoma virus CT10 oncogene homolog-like \\
\hline 143 & CCND3 & 6 & cyclin D3 \\
\hline 144 & STAT3 & 6 & $\begin{array}{c}\text { signal transducer and activator of transcription } 3 \text { (acute-phase response } \\
\text { factor) }\end{array}$ \\
\hline 145 & UGT1A1 & 6 & UDP glucuronosyltransferase 1 family, polypeptide A1 \\
\hline 197 & H3F3A & 6 & $\mathrm{H} 3$ histone, family $3 \mathrm{~A}$ \\
\hline 205 & PMS1 & 6 & PMS1 homolog 1, mismatch repair system component \\
\hline 251 & SBDS & 6 & Shwachman-Bodian-Diamond syndrome \\
\hline 252 & IKBKE & 6 & $\begin{array}{l}\text { inhibitor of kappa light polypeptide gene enhancer in B-cells, kinase } \\
\text { epsilon }\end{array}$ \\
\hline 253 & MAP3K1 & 6 & $\begin{array}{c}\text { mitogen-activated protein kinase kinase kinase 1, E3 ubiquitin protein } \\
\text { ligase }\end{array}$ \\
\hline 254 & TMPRSS2 & 6 & transmembrane protease, serine 2 \\
\hline 255 & HGF & 6 & hepatocyte growth factor (hepapoietin A; scatter factor) \\
\hline 308 & PIK3CD & 6 & phosphatidylinositol-4,5-bisphosphate 3-kinase, catalytic subunit delta \\
\hline 309 & NUP98 & 6 & nucleoporin $98 \mathrm{kDa}$ \\
\hline 310 & XPA & 6 & xeroderma pigmentosum, complementation group A \\
\hline 311 & COL1A1 & 6 & collagen, type I, alpha 1 \\
\hline 312 & RECQL4 & 6 & RecQ helicase-like 4 \\
\hline 313 & FOXP1 & 6 & forkhead box P1 \\
\hline 314 & CD79A & 6 & CD79a molecule \\
\hline 315 & PTGS2 & 6 & $\begin{array}{c}\text { prostaglandin-endoperoxide synthase } 2 \text { (prostaglandin } \mathrm{G} / \mathrm{H} \text { synthase and } \\
\text { cyclooxygenase) }\end{array}$ \\
\hline 316 & $\mathrm{NCOA} 2$ & 6 & nuclear receptor coactivator 2 \\
\hline 317 & IRS2 & 6 & insulin receptor substrate 2 \\
\hline
\end{tabular}




\begin{tabular}{|c|c|c|c|}
\hline 318 & CDK2 & 6 & cyclin-dependent kinase 2 \\
\hline 319 & BIRC5 & 6 & baculoviral IAP repeat containing 5 \\
\hline 320 & TOP2A & 6 & topoisomerase (DNA) II alpha \\
\hline 321 & RAD21 & 6 & RAD21 cohesin complex component \\
\hline 322 & PIK3C2B & 6 & phosphatidylinositol-4-phosphate 3-kinase catalytic subunit type 2 beta \\
\hline 323 & TMEM127 & 6 & transmembrane protein 127 \\
\hline 324 & REL & 6 & v-rel avian reticuloendotheliosis viral oncogene homolog \\
\hline 325 & SMC3 & 6 & structural maintenance of chromosomes 3 \\
\hline 326 & CBFB & 6 & core-binding factor, beta subunit \\
\hline 327 & EPHB1 & 6 & EPH receptor B1 \\
\hline 328 & SPOP & 6 & speckle type POZ protein \\
\hline 329 & AXIN2 & 6 & $\operatorname{axin} 2$ \\
\hline 330 & DEK & 6 & DEK proto-oncogene \\
\hline 331 & SMC1A & 6 & structural maintenance of chromosomes $1 \mathrm{~A}$ \\
\hline 332 & WRN & 6 & Werner syndrome, RecQ helicase-like \\
\hline 333 & SUZ12 & 6 & SUZ12 polycomb repressive complex 2 subunit \\
\hline 334 & POLD1 & 6 & polymerase (DNA directed), delta 1, catalytic subunit \\
\hline 335 & PML & 6 & promyelocytic leukemia \\
\hline 336 & HSP90AA1 & 6 & heat shock protein $90 \mathrm{kDa}$ alpha family class A member 1 \\
\hline 146 & EWSR1 & 5 & EWS RNA binding protein 1 \\
\hline 147 & CYP2D6 & 5 & cytochrome P450 family 2 subfamily D member 6 \\
\hline 148 & VEGFA & 5 & vascular endothelial growth factor A \\
\hline 149 & RPTOR & 5 & regulatory associated protein of MTOR, complex 1 \\
\hline 150 & SOX2 & 5 & SRY-box 2 \\
\hline 151 & ETV5 & 5 & ets variant 5 \\
\hline 256 & SMAD3 & 5 & SMAD family member 3 \\
\hline 257 & IGF2R & 5 & insulin like growth factor 2 receptor \\
\hline 258 & PAK3 & 5 & p21 protein $(\mathrm{Cdc} 42 / \mathrm{Rac})$-activated kinase 3 \\
\hline 259 & IGF2 & 5 & insulin like growth factor 2 \\
\hline 260 & BRD4 & 5 & bromodomain containing 4 \\
\hline 261 & HIF1A & 5 & $\begin{array}{l}\text { hypoxia inducible factor 1, alpha subunit (basic helix-loop-helix } \\
\text { transcription factor) }\end{array}$ \\
\hline 262 & HSP90AB1 & 5 & heat shock protein $90 \mathrm{kDa}$ alpha family class B member 1 \\
\hline 263 & FANCL & 5 & Fanconi anemia complementation group L \\
\hline 264 & CDKN1B & 5 & cyclin-dependent kinase inhibitor 1B (p27, Kip1) \\
\hline 265 & PDGFB & 5 & platelet-derived growth factor beta polypeptide \\
\hline 337 & CKS1B & 5 & $\mathrm{CDC} 28$ protein kinase regulatory subunit $1 \mathrm{~B}$ \\
\hline 338 & TET1 & 5 & tet methylcytosine dioxygenase 1 \\
\hline 339 & PBX1 & 5 & pre-B-cell leukemia homeobox 1 \\
\hline 340 & CREB1 & 5 & cAMP responsive element binding protein 1 \\
\hline 341 & PAX3 & 5 & paired box 3 \\
\hline
\end{tabular}




\begin{tabular}{|c|c|c|c|}
\hline 342 & DDIT3 & 5 & DNA damage inducible transcript 3 \\
\hline 343 & POT1 & 5 & protection of telomeres 1 \\
\hline 344 & NFKB1 & 5 & nuclear factor of kappa light polypeptide gene enhancer in B-cells 1 \\
\hline 345 & GRIN2A & 5 & glutamate receptor, ionotropic, $\mathrm{N}$-methyl D-aspartate 2A \\
\hline 346 & BCL3 & 5 & B-cell CLL/lymphoma 3 \\
\hline 347 & KLF6 & 5 & Kruppel-like factor 6 \\
\hline 348 & FUBP1 & 5 & far upstream element (FUSE) binding protein 1 \\
\hline 349 & MAP3K7 & 5 & mitogen-activated protein kinase kinase kinase 7 \\
\hline 350 & NUP214 & 5 & nucleoporin $214 \mathrm{kDa}$ \\
\hline 351 & SSX1 & 5 & synovial sarcoma, $\mathrm{X}$ breakpoint 1 \\
\hline 352 & BCL10 & 5 & B-cell CLL/lymphoma 10 \\
\hline 353 & BIRC2 & 5 & baculoviral IAP repeat containing 2 \\
\hline 354 & CDKN1A & 5 & cyclin-dependent kinase inhibitor 1A (p21, Cip1) \\
\hline 355 & ETS1 & 5 & v-ets avian erythroblastosis virus E26 oncogene homolog 1 \\
\hline 356 & $\mathrm{XRCC} 2$ & 5 & $\mathrm{X}$-ray repair complementing defective repair in Chinese hamster cells 2 \\
\hline 357 & CUX1 & 5 & cut-like homeobox 1 \\
\hline 358 & BCORL1 & 5 & BCL6 corepressor-like 1 \\
\hline 359 & TAL1 & 5 & T-cell acute lymphocytic leukemia 1 \\
\hline 360 & FLI1 & 5 & Fli-1 proto-oncogene, ETS transcription factor \\
\hline 361 & PRKDC & 5 & protein kinase, DNA-activated, catalytic polypeptide \\
\hline 362 & ADGRA2 & 5 & adhesion $\mathrm{G}$ protein-coupled receptor $\mathrm{A} 2$ \\
\hline 363 & EPHA7 & 5 & EPH receptor A7 \\
\hline 364 & EPHA5 & 5 & EPH receptor A5 \\
\hline 365 & BCL11B & 5 & B-cell CLL/lymphoma 11B (zinc finger protein) \\
\hline 366 & TCF12 & 5 & transcription factor 12 \\
\hline 367 & RAD51 & 5 & RAD51 recombinase \\
\hline 368 & CTNNA1 & 5 & catenin alpha 1 \\
\hline 369 & NOTCH4 & 5 & notch 4 \\
\hline 370 & EML4 & 5 & echinoderm microtubule associated protein like 4 \\
\hline 371 & MAML2 & 5 & mastermind like transcriptional coactivator 2 \\
\hline 372 & TRRAP & 5 & transformation/transcription domain-associated protein \\
\hline 373 & CDH11 & 5 & cadherin 11 , type 2 , OB-cadherin (osteoblast) \\
\hline 374 & MALT1 & 5 & MALT1 paracaspase \\
\hline 375 & LRP1B & 5 & LDL receptor related protein $1 \mathrm{~B}$ \\
\hline 376 & GLI1 & 5 & GLI family zinc finger 1 \\
\hline 377 & GPC3 & 5 & glypican 3 \\
\hline
\end{tabular}

Supplementary Table S4. Mutations in the pre-designed ctDNA panel

\begin{tabular}{llllll}
\hline gene & CDS Mutation & AA Mutation & chrom & start & end \\
\hline
\end{tabular}




\begin{tabular}{|c|c|c|c|c|c|}
\hline BRAF & c. $1803 \mathrm{~A}>\mathrm{T}$ & p.K601N & 7 & 140453132 & 140453132 \\
\hline BRAF & c. $1801 \mathrm{~A}>\mathrm{G}$ & p.K601E & 7 & 140453134 & 140453134 \\
\hline BRAF & c.1799_1801delTGA & p.V600_K601>E & 7 & 140453134 & 140453136 \\
\hline BRAF & c.1799_1800TG $>$ AA & p.V600E & 7 & 140453135 & 140453136 \\
\hline BRAF & c.1799_1800TG $>$ AT & p.V600D & 7 & 140453135 & 140453136 \\
\hline BRAF & c. $1799 \mathrm{~T}>\mathrm{A}$ & p.V600E & 7 & 140453136 & 140453136 \\
\hline BRAF & c.1798_1799GT>AA & p.V600K & 7 & 140453136 & 140453137 \\
\hline BRAF & c.1798_1799GT $>$ AG & p.V600R & 7 & 140453136 & 140453137 \\
\hline BRAF & c. $1799 \mathrm{~T}>\mathrm{C}$ & p.V600A & 7 & 140453136 & 140453136 \\
\hline BRAF & c. $1799 \mathrm{~T}>\mathrm{G}$ & p.V600G & 7 & 140453136 & 140453136 \\
\hline BRAF & c. $1798 \mathrm{G}>\mathrm{A}$ & p.V600M & 7 & 140453137 & 140453137 \\
\hline BRAF & c. $1790 \mathrm{~T}>\mathrm{G}$ & p.L597R & 7 & 140453145 & 140453145 \\
\hline BRAF & c. $1790 \mathrm{~T}>\mathrm{A}$ & p.L597Q & 7 & 140453145 & 140453145 \\
\hline BRAF & c.1789_1790CT $>\mathrm{TC}$ & p.L597S & 7 & 140453145 & 140453146 \\
\hline BRAF & c. $1789 \mathrm{C}>\mathrm{G}$ & p.L597V & 7 & 140453146 & 140453146 \\
\hline BRAF & c. $1786 \mathrm{G}>\mathrm{C}$ & p.G596R & 7 & 140453149 & 140453149 \\
\hline BRAF & c. $1781 \mathrm{~A}>\mathrm{G}$ & p.D594G & 7 & 140453154 & 140453154 \\
\hline BRAF & c. $1780 \mathrm{G}>\mathrm{A}$ & p.D594N & 7 & 140453155 & 140453155 \\
\hline BRAF & c. $1406 \mathrm{G}>\mathrm{C}$ & p.G469A & 7 & 140481402 & 140481402 \\
\hline BRAF & c. $1406 \mathrm{G}>\mathrm{T}$ & p.G469V & 7 & 140481402 & 140481402 \\
\hline BRAF & c. $1406 \mathrm{G}>\mathrm{A}$ & p.G469E & 7 & 140481402 & 140481402 \\
\hline BRAF & c. $1405 \mathrm{G}>\mathrm{A}$ & p.G469R & 7 & 140481403 & 140481403 \\
\hline BRAF & c. $1397 \mathrm{G}>\mathrm{T}$ & p.G466V & 7 & 140481411 & 140481411 \\
\hline BRAF & c. $1397 \mathrm{G}>\mathrm{A}$ & p.G466E & 7 & 140481411 & 140481411 \\
\hline EGFR & c. $865 \mathrm{G}>\mathrm{A}$ & p.A289T & 7 & 55221821 & 55221821 \\
\hline EGFR & c. $866 \mathrm{C}>\mathrm{T}$ & p.A289V & 7 & 55221822 & 55221822 \\
\hline EGFR & c. $1793 \mathrm{G}>\mathrm{T}$ & p.G598V & 7 & 55233043 & 55233043 \\
\hline EGFR & c. $2125 \mathrm{G}>\mathrm{A}$ & p.E709K & 7 & 55241677 & 55241677 \\
\hline EGFR & c. $2126 \mathrm{~A}>\mathrm{C}$ & p.E709A & 7 & 55241678 & 55241678 \\
\hline EGFR & c. $2155 \mathrm{G}>\mathrm{A}$ & p.G719S & 7 & 55241707 & 55241707 \\
\hline EGFR & c. $2155 \mathrm{G}>\mathrm{T}$ & p.G719C & 7 & 55241707 & 55241707 \\
\hline EGFR & c. $2156 \mathrm{G}>\mathrm{C}$ & p.G719A & 7 & 55241708 & 55241708 \\
\hline EGFR & c.2235_2249del15 & p.E746_A750delELREA & 7 & 55242465 & 55242479 \\
\hline EGFR & c.2236_2250del15 & p.E746_A750delELREA & 7 & 55242466 & 55242480 \\
\hline EGFR & c.2237_2255>T & p.E746_S752>V & 7 & 55242467 & 55242485 \\
\hline EGFR & c. $2237 \_2251 \mathrm{del} 15$ & p.E746_T751>A & 7 & 55242467 & 55242481 \\
\hline EGFR & c.2239_2248TTAAGAGAAG $>$ C & p.L747_A750>P & 7 & 55242469 & 55242478 \\
\hline EGFR & c.2239_2256del18 & p.L747_S752delLREATS & 7 & 55242469 & 55242486 \\
\hline EGFR & c.2239_2251>C & p.L747_T751>P & 7 & 55242469 & 55242481 \\
\hline EGFR & c. $2239 \_2253 \mathrm{del} 15$ & p.L747_T751delLREAT & 7 & 55242469 & 55242483 \\
\hline EGFR & c.2239_2247delTTAAGAGAA & p.L747_E749delLRE & 7 & 55242469 & 55242477 \\
\hline EGFR & c. $2240 \_2257 \mathrm{del} 18$ & p.L747_P753>S & 7 & 55242470 & 55242487 \\
\hline EGFR & c. $2240 \_2254 \mathrm{del} 15$ & p.L747_T751delLREAT & 7 & 55242470 & 55242484 \\
\hline
\end{tabular}




\begin{tabular}{|c|c|c|c|c|c|}
\hline EGFR & c. $2240 \mathrm{~T}>\mathrm{C}$ & p.L747S & 7 & 55242470 & 55242470 \\
\hline EGFR & c.2254_2277del24 & p.S752_I759delSPKANKEI & 7 & 55242484 & 55242507 \\
\hline EGFR & c. $2290 \_2291 \mathrm{ins} 12$ & p.A763_Y764insFQEA & 7 & 55248992 & 55248993 \\
\hline EGFR & c. $2303 \mathrm{G}>\mathrm{T}$ & p.S768I & 7 & 55249005 & 55249005 \\
\hline EGFR & c.2307_2308insGCCAGCGTG & p.V769_D770insASV & 7 & 55249009 & 55249010 \\
\hline EGFR & c.2308_2309insCCAGCGTGG & p.V769_D770insASV & 7 & 55249010 & 55249011 \\
\hline EGFR & c.2311_2312insGCGTGGACA & p.D770_N771insSVD & 7 & 55249013 & 55249014 \\
\hline EGFR & c.2319_2320insAACCCCCAC & p.H773_V774insNPH & 7 & 55249021 & 55249022 \\
\hline EGFR & c. $2369 \mathrm{C}>\mathrm{T}$ & p.T790M & 7 & 55249071 & 55249071 \\
\hline EGFR & c. $2497 \mathrm{~T}>\mathrm{G}$ & p.L833V & 7 & 55259439 & 55259439 \\
\hline EGFR & c. $2504 \mathrm{~A}>\mathrm{T}$ & p.H835L & 7 & 55259446 & 55259446 \\
\hline EGFR & c. $2543 \mathrm{C}>\mathrm{T}$ & p.P848L & 7 & 55259485 & 55259485 \\
\hline EGFR & c. $2573 \mathrm{~T}>\mathrm{G}$ & p.L858R & 7 & 55259515 & 55259515 \\
\hline EGFR & c. $2582 \mathrm{~T}>\mathrm{A}$ & p.L861Q & 7 & 55259524 & 55259524 \\
\hline ERBB2 & c. $929 \mathrm{C}>\mathrm{T}$ & p.S310F & 17 & 37868208 & 37868208 \\
\hline ERBB2 & c. $1963 \mathrm{~A}>\mathrm{G}$ & p.I655V & 17 & 37879588 & 37879588 \\
\hline ERBB2 & c. $2033 \mathrm{G}>\mathrm{A}$ & p.R678Q & 17 & 37879658 & 37879658 \\
\hline ERBB2 & c. $2264 \mathrm{~T}>\mathrm{C}$ & p.L755S & 17 & 37880220 & 37880220 \\
\hline ERBB2 & c. $2324 \_2325$ ins 12 & p.A775_G776insYVMA & 17 & 37880995 & 37880996 \\
\hline ERBB2 & c. $2325 \_2326$ ins 12 & p.A775_G776insYVMA & 17 & 37880996 & 37880997 \\
\hline ERBB2 & c. $2524 \mathrm{G}>\mathrm{A}$ & p.V842I & 17 & 37881332 & 37881332 \\
\hline KIT & c.1255_1257delGAC & p.D419del & 4 & 55589773 & 55589775 \\
\hline KIT & c.1509_1510insGCCTAT & p.Y503_F504insAY & 4 & 55592185 & 55592186 \\
\hline KIT & c.1669_1674delTGGAAG & p.W557_K558del & 4 & 55593603 & 55593608 \\
\hline KIT & c. $1669 \mathrm{~T}>\mathrm{G}$ & p.W557G & 4 & 55593603 & 55593603 \\
\hline KIT & c. $1669 \mathrm{~T}>\mathrm{C}$ & p.W557R & 4 & 55593603 & 55593603 \\
\hline KIT & c. $1669 \mathrm{~T}>\mathrm{A}$ & p.W557R & 4 & 55593603 & 55593603 \\
\hline KIT & c.1669_1683del15 & p.W557_E561del & 4 & 55593603 & 55593617 \\
\hline KIT & c.1670_1675delGGAAGG & p.W557_V559>F & 4 & 55593604 & 55593609 \\
\hline KIT & c.1675_1677delGTT & p.V559del & 4 & 55593609 & 55593611 \\
\hline KIT & c. $1676 \mathrm{~T}>\mathrm{A}$ & p.V559D & 4 & 55593610 & 55593610 \\
\hline KIT & c. $1676 \mathrm{~T}>\mathrm{C}$ & p.V559A & 4 & 55593610 & 55593610 \\
\hline KIT & c. $1676 \mathrm{~T}>\mathrm{G}$ & p.V559G & 4 & 55593610 & 55593610 \\
\hline KIT & c.1678_1680delGTT & p.V560del & 4 & 55593612 & 55593614 \\
\hline KIT & c. $1679 \mathrm{~T}>\mathrm{A}$ & p.V560D & 4 & 55593613 & 55593613 \\
\hline KIT & c. $1679 \mathrm{~T}>\mathrm{G}$ & p.V560G & 4 & 55593613 & 55593613 \\
\hline KIT & c. $1727 \mathrm{~T}>\mathrm{C}$ & p.L576P & 4 & 55593661 & 55593661 \\
\hline KIT & c.1735_1737delGAT & p.D579del & 4 & 55593669 & 55593671 \\
\hline KIT & c. $1924 \mathrm{~A}>\mathrm{G}$ & p.K642E & 4 & 55594221 & 55594221 \\
\hline KIT & c. $1961 \mathrm{~T}>\mathrm{C}$ & p.V654A & 4 & 55594258 & 55594258 \\
\hline KIT & c. $2009 \mathrm{C}>\mathrm{T}$ & p.T670I & 4 & 55595519 & 55595519 \\
\hline KIT & c. $2387 \mathrm{G}>\mathrm{A}$ & p.R796K & 4 & 55599261 & 55599261 \\
\hline KIT & c. $2446 \mathrm{G}>\mathrm{T}$ & p.D816Y & 4 & 55599320 & 55599320 \\
\hline
\end{tabular}




\begin{tabular}{|c|c|c|c|c|c|}
\hline KIT & c. $2446 \mathrm{G}>\mathrm{C}$ & p.D816H & 4 & 55599320 & 55599320 \\
\hline KIT & c. $2447 \mathrm{~A}>\mathrm{T}$ & p.D816V & 4 & 55599321 & 55599321 \\
\hline KIT & c. $2466 \mathrm{~T}>\mathrm{G}$ & p.N822K & 4 & 55599340 & 55599340 \\
\hline KIT & c. $2466 \mathrm{~T}>\mathrm{A}$ & p.N822K & 4 & 55599340 & 55599340 \\
\hline KIT & c. $2474 \mathrm{~T}>\mathrm{C}$ & p.V825A & 4 & 55599348 & 55599348 \\
\hline KIT & c. $2485 \mathrm{G}>\mathrm{C}$ & p.A829P & 4 & 55602664 & 55602664 \\
\hline KRAS & c. $437 \mathrm{C}>\mathrm{T}$ & p.A146V & 12 & 25378561 & 25378561 \\
\hline KRAS & c. $436 \mathrm{G}>\mathrm{A}$ & p.A146T & 12 & 25378562 & 25378562 \\
\hline KRAS & c. $351 \mathrm{~A}>\mathrm{T}$ & p.K117N & 12 & 25378647 & 25378647 \\
\hline KRAS & c. $351 \mathrm{~A}>\mathrm{C}$ & p.K117N & 12 & 25378647 & 25378647 \\
\hline KRAS & c. $183 \mathrm{~A}>\mathrm{C}$ & p.Q61H & 12 & 25380275 & 25380275 \\
\hline KRAS & c. $183 \mathrm{~A}>\mathrm{T}$ & p.Q61H & 12 & 25380275 & 25380275 \\
\hline KRAS & c. $182 \mathrm{~A}>\mathrm{T}$ & p.Q61L & 12 & 25380276 & 25380276 \\
\hline KRAS & c. $182 \mathrm{~A}>\mathrm{G}$ & p.Q61R & 12 & 25380276 & 25380276 \\
\hline KRAS & c. $182 \mathrm{~A}>\mathrm{C}$ & p.Q61P & 12 & 25380276 & 25380276 \\
\hline KRAS & c. $181 \mathrm{C}>\mathrm{A}$ & p.Q61K & 12 & 25380277 & 25380277 \\
\hline KRAS & c. $181 \mathrm{C}>\mathrm{G}$ & p.Q61E & 12 & 25380277 & 25380277 \\
\hline KRAS & c. $175 \mathrm{G}>\mathrm{A}$ & p.A59T & 12 & 25380283 & 25380283 \\
\hline KRAS & c. $64 \mathrm{C}>\mathrm{A}$ & p.Q22K & 12 & 25398255 & 25398255 \\
\hline KRAS & c. $57 \mathrm{G}>\mathrm{T}$ & p.L19F & 12 & 25398262 & 25398262 \\
\hline KRAS & c. $40 \mathrm{G}>\mathrm{A}$ & p.V14I & 12 & 25398279 & 25398279 \\
\hline KRAS & c. $38 \_39 \mathrm{GC}>\mathrm{AT}$ & p.G13D & 12 & 25398280 & 25398281 \\
\hline KRAS & c. $38 \mathrm{G}>\mathrm{A}$ & p.G13D & 12 & 25398281 & 25398281 \\
\hline KRAS & c. $38 \mathrm{G}>\mathrm{C}$ & p.G13A & 12 & 25398281 & 25398281 \\
\hline KRAS & c. $38 \mathrm{G}>\mathrm{T}$ & p.G13V & 12 & 25398281 & 25398281 \\
\hline KRAS & c. $37 \mathrm{G}>\mathrm{T}$ & p.G13C & 12 & 25398282 & 25398282 \\
\hline KRAS & c. $37 \mathrm{G}>\mathrm{A}$ & p.G13S & 12 & 25398282 & 25398282 \\
\hline KRAS & c. $37 \mathrm{G}>\mathrm{C}$ & p.G13R & 12 & 25398282 & 25398282 \\
\hline KRAS & c. $35 \mathrm{G}>\mathrm{A}$ & p.G12D & 12 & 25398284 & 25398284 \\
\hline KRAS & c. $35 \mathrm{G}>\mathrm{T}$ & p.G12V & 12 & 25398284 & 25398284 \\
\hline KRAS & c. $35 \mathrm{G}>\mathrm{C}$ & p.G12A & 12 & 25398284 & 25398284 \\
\hline KRAS & c. $34 \_35 \mathrm{GG}>\mathrm{TT}$ & p.G12F & 12 & 25398284 & 25398285 \\
\hline KRAS & c.34_35GG $>\mathrm{CT}$ & p.G12L & 12 & 25398284 & 25398285 \\
\hline KRAS & c. $34 \mathrm{G}>\mathrm{T}$ & p.G12C & 12 & 25398285 & 25398285 \\
\hline KRAS & c. $34 \mathrm{G}>\mathrm{A}$ & p.G12S & 12 & 25398285 & 25398285 \\
\hline KRAS & c. $34 \mathrm{G}>\mathrm{C}$ & p.G12R & 12 & 25398285 & 25398285 \\
\hline MET & c. $1124 \mathrm{~A}>\mathrm{G}$ & p.N375S & 7 & 116340262 & 116340262 \\
\hline MET & c. $3029 \mathrm{C}>\mathrm{T}$ & p.T1010I & 7 & 116411990 & 116411990 \\
\hline MET & MET exon 14 skipping & MET exon 14 skipping & 7 & 116412042 & 116412042 \\
\hline MET & MET exon 14 skipping & MET exon 14 skipping & 7 & 116412043 & 116412043 \\
\hline MET & MET exon 14 skipping & MET exon 14 skipping & 7 & 116412044 & 116412044 \\
\hline MET & MET exon 14 skipping & MET exon 14 skipping & 7 & 116412045 & 116412045 \\
\hline MET & c. $3757 \mathrm{~T}>\mathrm{G}$ & p.Y1253D & 7 & 116423428 & 116423428 \\
\hline
\end{tabular}




\begin{tabular}{|c|c|c|c|c|c|}
\hline MET & c. $3803 \mathrm{~T}>\mathrm{C}$ & p.M1268T & 7 & 116423474 & 116423474 \\
\hline NRAS & c. $183 \mathrm{~A}>\mathrm{T}$ & p.Q61H & 1 & 115256528 & 115256528 \\
\hline NRAS & c. $183 \mathrm{~A}>\mathrm{C}$ & p.Q61H & 1 & 115256528 & 115256528 \\
\hline NRAS & c. $182 \mathrm{~A}>\mathrm{G}$ & p.Q61R & 1 & 115256529 & 115256529 \\
\hline NRAS & c. $182 \mathrm{~A}>\mathrm{T}$ & p.Q61L & 1 & 115256529 & 115256529 \\
\hline NRAS & c. $182 \mathrm{~A}>\mathrm{C}$ & p.Q61P & 1 & 115256529 & 115256529 \\
\hline NRAS & c. $181 \mathrm{C}>\mathrm{A}$ & p.Q61K & 1 & 115256530 & 115256530 \\
\hline NRAS & c. $181 \mathrm{C}>\mathrm{G}$ & p.Q61E & 1 & 115256530 & 115256530 \\
\hline NRAS & c. $52 \mathrm{G}>\mathrm{A}$ & p.A18T & 1 & 115258730 & 115258730 \\
\hline NRAS & c. $38 \mathrm{G}>\mathrm{A}$ & p.G13D & 1 & 115258744 & 115258744 \\
\hline NRAS & c. $38 \mathrm{G}>\mathrm{T}$ & p.G13V & 1 & 115258744 & 115258744 \\
\hline NRAS & c. $38 \mathrm{G}>\mathrm{C}$ & p.G13A & 1 & 115258744 & 115258744 \\
\hline NRAS & c. $37 \mathrm{G}>\mathrm{C}$ & p.G13R & 1 & 115258745 & 115258745 \\
\hline NRAS & c. $37 \mathrm{G}>\mathrm{T}$ & p.G13C & 1 & 115258745 & 115258745 \\
\hline NRAS & c. $35 \mathrm{G}>\mathrm{A}$ & p.G12D & 1 & 115258747 & 115258747 \\
\hline NRAS & c. $35 \mathrm{G}>\mathrm{T}$ & p.G12V & 1 & 115258747 & 115258747 \\
\hline NRAS & c. $35 \mathrm{G}>\mathrm{C}$ & p.G12A & 1 & 115258747 & 115258747 \\
\hline NRAS & c. $34 \mathrm{G}>\mathrm{A}$ & p.G12S & 1 & 115258748 & 115258748 \\
\hline NRAS & c. $34 \mathrm{G}>\mathrm{T}$ & p.G12C & 1 & 115258748 & 115258748 \\
\hline NRAS & c. $34 \mathrm{G}>\mathrm{C}$ & p.G12R & 1 & 115258748 & 115258748 \\
\hline PIK3CA & c.G241A & p.E81K & 3 & 178916854 & 178916854 \\
\hline PIK3CA & c. $263 \mathrm{G}>\mathrm{A}$ & p.R88Q & 3 & 178916876 & 178916876 \\
\hline PIK3CA & c.C277T & p.R93W & 3 & 178916890 & 178916890 \\
\hline PIK3CA & c.G317T & p.G106V & 3 & 178916930 & 178916930 \\
\hline PIK3CA & c.G323A & p.R108H & 3 & 178916936 & 178916936 \\
\hline PIK3CA & c.A331G & p.K111E & 3 & 178916944 & 178916944 \\
\hline PIK3CA & c.G353A & p.G118D & 3 & 178917478 & 178917478 \\
\hline PIK3CA & c. $1035 \mathrm{~T}>\mathrm{A}$ & p.N345K & 3 & 178921553 & 178921553 \\
\hline PIK3CA & c. $1258 \mathrm{~T}>\mathrm{C}$ & p.C420R & 3 & 178927980 & 178927980 \\
\hline PIK3CA & c. $1616 C>G$ & p.P539R & 3 & 178936074 & 178936074 \\
\hline PIK3CA & c. $1624 \mathrm{G}>\mathrm{A}$ & p.E542K & 3 & 178936082 & 178936082 \\
\hline PIK3CA & c. $1633 \mathrm{G}>\mathrm{A}$ & p.E545K & 3 & 178936091 & 178936091 \\
\hline PIK3CA & c. $1633 \mathrm{G}>\mathrm{C}$ & p.E545Q & 3 & 178936091 & 178936091 \\
\hline PIK3CA & c. $1634 \mathrm{~A}>\mathrm{C}$ & p.E545A & 3 & 178936092 & 178936092 \\
\hline PIK3CA & c. $1634 \mathrm{~A}>\mathrm{G}$ & p.E545G & 3 & 178936092 & 178936092 \\
\hline PIK3CA & c. $1635 \mathrm{G}>\mathrm{T}$ & p.E545D & 3 & 178936093 & 178936093 \\
\hline PIK3CA & c. $1635 \mathrm{G}>\mathrm{C}$ & p.E545D & 3 & 178936093 & 178936093 \\
\hline PIK3CA & c. $1636 \mathrm{C}>\mathrm{A}$ & p.Q546K & 3 & 178936094 & 178936094 \\
\hline PIK3CA & c. $1636 C>G$ & p.Q546E & 3 & 178936094 & 178936094 \\
\hline PIK3CA & c. $1637 \mathrm{~A}>\mathrm{G}$ & p.Q546R & 3 & 178936095 & 178936095 \\
\hline PIK3CA & c. $1637 \mathrm{~A}>\mathrm{C}$ & p.Q546P & 3 & 178936095 & 178936095 \\
\hline PIK3CA & c.G1639A & p.E547K & 3 & 178936097 & 178936097 \\
\hline PIK3CA & c. $3062 \mathrm{~A}>\mathrm{G}$ & p.Y1021C & 3 & 178952007 & 178952007 \\
\hline
\end{tabular}




\begin{tabular}{lccccc}
\hline PIK3CA & c.3073A $>$ G & p.T1025A & 3 & 178952018 & 178952018 \\
PIK3CA & c.3127A $>$ G & p.M1043V & 3 & 178952072 & 178952072 \\
PIK3CA & c.3129G $>$ T & p.M1043I & 3 & 178952074 & 178952074 \\
PIK3CA & c.G3129A & p.M1043I & 3 & 178952074 & 178952074 \\
PIK3CA & c.T3132A & p.N1044K & 3 & 178952077 & 178952077 \\
PIK3CA & c.3139C $>$ T & p.H1047Y & 3 & 178952084 & 178952084 \\
PIK3CA & c.3140A $>$ G & p.H1047R & 3 & 178952085 & 178952085 \\
PIK3CA & c.3140A $>$ T & p.H1047L & 3 & 178952085 & 178952085 \\
PIK3CA & c.3145G $>C$ & p.G1049R & 3 & 178952090 & 178952090 \\
PIK3CA & c.3145G $>$ A & p.G1049S & 3 & 178952090 & 178952090 \\
\hline
\end{tabular}

\section{References and notes}

1. Singavi, A. K., S. Menon, D. Kilari, A. Alqwasmi, P. S. Ritch, J. P. Thomas, A. L. Martin, C. Oxencis, S. Ali, B. George. 1140PDPredictive biomarkers for hyperprogression (HP) in response to immune checkpoint inhibitors (ICI)-analysis of somatic alterations (SAs). Annal. Oncol. 28, suppl 5 (2017).

2. Umelo, I.A., B. Costanza, V. Castronovo. Innovative methods for biomarker discovery in the evaluation and development of cancer precision therapies. Cancer Metastasis Rev. 37, 125-145 (2018).

3. Sawyers, C. L. The cancer biomarker problem. Nature 452, 548-552 (2008).

4. Wan, J. C., C. Massie, J. Garcia-Corbacho, F. Mouliere, J. D. Brenton, C. Caldas, S. Pacey, R. Baird, N. Rosenfed. Liquid biopsies come of age: towards implementation of circulating tumour DNA. Nat. Rev. Cancer 17, 223-238 (2017).

5. Tie, J., I. Kinde, Y. Wang, H. L. Wong, J. Roebert, M. Christie, M. Tacey, R. Wong, M. Singh, C. S. Karapetis, J. Desai, B. Tran, R. L. Strausberg, L. A. Diaz Jr., N. Papadopoulos, K. W. Kinzler, B. Vogelstein, P. Gibbs. Circulating tumor DNA as an early marker of therapeutic response in patients with metastatic colorectal cancer. Ann. Oncol. 26, 1715-1722 (2015).

6. Riva, F., F. C. Bidard, H. Houy, A. Saliou, J. Madic, A. Rampanou, C. Hego, M. Milder, P. Cottu, M. P. Sablin, A. Vincent-Salomon, O. Lantz, M. H. Stern, C. Proudhon, J. Y. Pierga. Patient-specific circulating tumor DNA detection during neoadjuvant chemotherapy in triple-negative breast cancer. Clin. Chem. 63, 691-699 (2017).

7. Corcoran, R. B., T. André, C. E. Atreya, J. H. M. Schellens, T. Yoshino, J. C. Bendell, A. Hollebecque, A. J. McRee, S. Siena, G. Middleton, K. Muro, M. S. Gordon, J. Tabernero, R. Yaeger, P. J. O'Dwyer, Y. Humblet, F. De Vos, A. S. Jung, J. C. Brase, S. Jaeger, S. Bettinger, B. Mookerjee, F. Rangwala, E. Van Cutsem. Combined BRAF, EGFR, and MEK inhibition in patients with BRAF V600E-mutant colorectal cancer. Cancer Discov. 8, 428-443 (2018). 
8. Abbosh, C., N. J. Birkback, G. A. Wilson, M. Jamal-Hanjani, T. Constantin, R. Salari, J. Le Quesne, D. A. Moore, S. Veeriah, R. Rosenthal, T. Marfioti, E. Kirkiziar, T. B. K. Watkins, N. McGranahan, S. Ward, L. Martinson, J. Riley, F. Fraioli, M. Al Bakir, E. Grönroos, F. Zambrana, R. Endozo, W. L. Bi, F. M. Fennessy, N. Sponer, D. Johnson, J. Laycock, S. Shafi, J. Czyzewska-Khan, A. Rowan, T. Chambers, N. Matthews, S. Turajilic, C. Hiley, S. M. Lee, M. D. Forster, T. Ahmad, M. Falzon, E. Borg, D. Lawrence, M. Hayward, S. Kolvekar, N. Panagiotopoulos, S. M. Janes, R. Thakrar, A. Ahmed, F. Blackhall, Y. Summers, D. Hafez, A. Naik, A. Gaguly, S. Kareht, R. Shah, L. Joseph, A. Marie Quinn, P. A. Crosbie, B. Naidu, G. Middleton, G. Langman, S. Trotter, M. Nicolson, H. Remmen, K. Kerr, M. Chetty, L. Gomersall, D. A. Fennell, A. Nakas, S. Rathinam, G. Anand, S. Khan, P. Russell, V. Ezhil, B. Ismail, M. Irvin-Sellers, V. Prakash, J. F. Lester, M. Kornaszewska, R. Attanoos, H. Adams, H. Davies, D. Oukrif, A. U. Akarca, J. A. Hartley, H. L. Lowe, S. Lock, N. Iles, H. Bell, Y. Ngai, G. Elgars, Z. Szallasi, R. F. Scharz, J. Herrero, A. Stewart, S. A. Quezada, K. S. Peggs, P. Van Loo, C. Dive, C. J. Lin, M. Rabinowitz, H. J. W. L. Aerts, A. Hackshaw, J. A. Shaw, B. G. Zimmerman; TRACERx consortium; PEAC consortium; C. Swanton. Phylogenetic ctDNA analysis depicts early-stage lung cancer evolution. Nature 545, 446-551 (2017).

9. McDonald, B. R., T. Contente-Cuomo, S. J. Sammut, A. Odenheimer-Bergman, B. Ernst, N. Perdigones, S. F. Chin, M. Farooq, P. A. Cronin, K. S. Anderson, H. E. Kosiorek, D. W. Northfelt, A. E. McCullough, B. K. Patel, C. Caldas, B. A. Pockaj, M. Murtaza. Detection of residual disease after neoadjuvant therapy in breast cancer using personalized circulating tumor DNA analysis. bioRxiv 425470 (2018).

10. Miller, C. A., B. S. White, N. D. Dees, M. Griffith, J. S. Welch, O. L. Griffith, R. Vij, M. H. Tomasson, T. A. Graubert, M. J. Walter, M. J. Ellis, W. Schierding, J. F. DiPersio, T. J. Ley, E. R. Mardis, R. K. Wilson, L. Ding. SciClone: inferring clonal architecture and tracking the spatial and temporal patterns of tumor evolution. PLoS Comput. Biol. 10, e1003665 (2014).

11. Update civic priority genes from commercial panel. Available from: https://github.com/griffithlab/civicserver/blob/master/public/downloads/RankedCivicGeneCandidates.tsv.

12. Corcoran, R. B., B. A. Chabner. Application of cell-free DNA analysis to cancer treatment. N. Engl. J. Med. 379, 1754-1765 (2018).

13. Merker, J. D., G. R. Oxnard, C. Compton, M. Diehn, P. Hurley, A. J. Lazar, N. Lindeman, C. M. Lockwood, A. J. Rai, R. L. Schilsky, A. M. Tsimberidou, P. Vasalos, B. L. Billman, T. K. Oliver, S. S. Bruinooge, D. F. Hayes, N. C. Turner. Circulating tumor DNA analysis in patients with cancer: American Society of Clinical Oncology and College of American Pathologists joint review. Arch. Pathol. Lab. Med. 142, 1242-1253 (2018).

14. Zill, O. A., K. C. Banks, S. R. Fairclough, S. A. Mortimer, J. V. Vowles, R. Mokhtari, D. R. Gandara, P. C. Mack, J. I. Odegaard, R. J. Nagy, A. M. Baca, H. Eltoukhy, D. I. Chudova, R. B. Lanman, A. Talasaz. The landscape of actionable genomic alterations in cell-free circulating tumor DNA from 21,807 advanced cancer patients. Clin. Cancer Res. 24, 3528-3538 (2018). 
15. Tie, J., Y. Wang, C. Tomasetti, L. Li, S. Springer, I. Kinde, N. Silliman, M. Tacey, H. L. Wong, M. Christie, S. Kosmider, I. Skinner, R. Wong, M. Steel, B. Tran, J. Desai, I. Jones, A. Haydon, T. Hayes, T. J. Price, R. L. Strausberg, L. A. Diaz Jr., N. Papadopoulos, K. W. Kinzler, B. Vogelstein, P. Gibbs. Circulating tumor DNA analysis detects minimal residual disease and predicts recurrence in patients with stage II colon cancer. Sci. Transl. Med. 8, 346ra92 (2016).

16. Reinert, T., L. V. Schøler, R. Thomsen, H. Tobiasen, S. Vang, I. Nordentoft, P. Lamy, A. S. Kannerup, F. V. Mortensen, K. Stribolt, S. Hamilton-Dutoit, H. J. Nielsen, S. Laurberg, N. Pallisgaard, J. S. Pedersen, T. F. Ørtoft, C. L. Andersen. Analysis of circulating tumour DNA to monitor disease burden following colorectal cancer surgery. Gut 65, 625-634 (2016).

17. Hsu, H.- C., N. Lapke, C. W. Wang, P. Y. Lin, J. F. You, C. Y. Yeh, W. S. Tsai, H. Y. Hung, S. F. Chiang, H. C. Chen, S. J. Chen, A. Hsu, T. S. Yang. Targeted sequencing of circulating tumor DNA to monitor genetic variants and therapeutic response in metastatic colorectal cancer. Mol. Cancer Ther. 17, 2238-2247 (2018).

18. Dawson, S.- J., D. W. Tsui, M. Murtaza, H. Biggs, O. M. Rueda, S. F. Chin, M. J. Dunning, D. Gale, T. Forshew, B. Mahler-Araujo, S. Rajan, S. Humphray, J. Becq, D. Halsall, M. Wallis, D. Bentley, C. Caldas, N. Rosenfeld. Analysis of circulating tumor DNA to monitor metastatic breast cancer. N. Engl. J. Med. 368, 1199-1209 (2013).

19. Birkenkamp-Demtröder, K., E. Christensen, I. Nordentoft, M. Knudsen, A. Taber, S. Høyer, P. Lamy, M. Agerbæk, J. B. Jensen, L. Dryskjøt. Monitoring treatment response and metastatic relapse in advanced bladder cancer by liquid biopsy analysis. Eur. Urol. 73, 535-540 (2018).

20. Hargadon, K. M., C. E. Johnson, and C. J. Williams. Immune checkpoint blockade therapy for cancer: an overview of FDA-approved immune checkpoint inhibitors. Int. Immunopharmacol. 62, 29-39 (2018).

21. Markovic, S. N., A. B. Kumar. Therapeutic targets of FDA-approved immunotherapies in oncology. In The Basics of Cancer Immunotherapy (Springer, 2018) pp. 21-37.

22. Giroux Leprieur, E., G. Herbretau, C. Dumenil, C. Julie, V. Giraud, S. Labrune, J. Dumoulin, J. Tisserand, J. F. Emilie, H. Blons, T. Chinet. Circulating tumor DNA evaluated by next-generation sequencing is predictive of tumor response and prolonged clinical benefit with nivolumab in advanced non-small cell lung cancer.

Oncoimmunology. 7, e1424675 (2018).

23. Lee, J. H., G. V. Long, A. M. Menzies, S. Lo, A. Guminski, K. Whitbourne, M. Peranec, R. Scolyer, R. F. Kefford, H. Rizos, M. S. Carlino. Association between circulating tumor DNA and pseudoprogression in patients with metastatic melanoma treated with anti-programmed cell death 1 antibodies. JAMA Oncol. 4, 717-721 (2018).

24. Christensen, E., K. Birkenkamp-Demtröder, H. Sethi, S. Shchegrova, R. Salari, I. Nordentoft, H. T. Wu, M. Knudsen, P. Lamy, S. V. Lindskrog, A. Taber, M. Balcioglu, S. Vang, Z. Assaf, S. Sharma, A. S. Tin, R. Srinivasan, D. Hafez, T. Reinert, S. Navarro, A. Olson, R. Ram, S. Dashner, M. Rabinowitz, P. Billings, s. Sigurjonsson, C. L. Andersen, R. Senerton, A. Aleshin, B. Zimmermann, M. Agerbæk, C. J. Lin, J. B. Jensen, L. Dyrskjøt. Early detection of metastatic relapse and monitoring of therapeutic efficacy 
by ultra-deep sequencing of plasma cell-free DNA in patients with urothelial bladder carcinoma. J. Clin. Oncol. 37, 1547-1557 (2019).

25. Abbosh, C., N. J. Birkbak, C. Swanton. Early stage NSCLC — challenges to implementing ctDNA-based screening and MRD detection. Nat. Rev. Clin. Oncol. 15, 577-586 (2018).

26. Chaudhuri, A. A., J. J. Chabon, A. F. Lovejoy, A. M. Newman, H. Stehr, T. D. Azad, M. s. Khodadoust, M. S. Esfahani, C. L. Liu, L. Zhou, F. Scherer, D. M. Kurtz, C. Say, J. N. Carter, D. J. Merriott, J. C. Dudley, M. S. Binkley, L. Modlin, S. K. Padda, M. F. Gensheimer, R. B. West, J. B. Shrager, J. W. Neal, H. A. Wakelee, B. W. Loo Jr., A. A. Alizadeh, M. Diehn. Early detection of molecular residual disease in localized lung cancer by circulating tumor DNA profiling. Cancer Discov. 7, 1394-1403 (2017).

27. Kurtz, D. M., F. Scherer, M. C. Jin, J. Soo, A. F. M. Craig, M. S. Esfahani, J. J. Chabon, H. Stehr, C. L. Liu, R. Tibshirani, L. S. Maeda, N. K. Gupta, M. S. Khodadoust, R. H. Advani, R. Levy, A. M. Newman, U. Dührsen, A. Hüttmann, M. Meignan, R. O. Casasnovas, J. R. Westin, M. Roschewski, W. H. Wilson, G. Gaidano, D. Rossi, M. Diehn, A. A. Alizadeh. Circulating tumor DNA measurements as early outcome predictors in diffuse large B-cell lymphoma. J. Clin. Oncol. 36, 2845-2853 (2018).

28. Phallen, J., M. Sausen, V. Adleff, A. Leal, C. Hruban, J. White, V. Anagnostou, J. Fiksel, S. Cristiano, E. Papp, S. Speir, T. Reinert, M. W. Orntoft, B. D. Woodward, D. Murphy, S. Parpart-Li, D. Riley, M. Nessenlbush, N. Sengamalay, A. Georgiadis, Q. K. Li, M. R. Madsen, F. V. Mortensen, J. Huiskens, C. Punt, N. van Grieken, r. Fijneman, G. Meijer, H. Husain, R. B. Scharpf, L. A. Diaz Jr., S. Jones, S. Angiuoli, T. Ørtoft, H. J. Nielsen, C. L. Andersen, V. E. Velculescu. Direct detection of early-stage cancers using circulating tumor DNA. Sci. Transl. Med. 9, eaan2415 (2017).

29. Razavi, P., B. T. Li, C. Hou, R. Shen, O. Venn, R. S. Lim, E. Hubbell, I. De Bruijn, Q. Liu, R. Vijaya Satya, H. Xu, L. Shen, A. Shenert, T. Maddala, M. F. Berger, A. Aravanis, J. S. Reis-Filho, M. Lee, D. B. solit, J. Baselga. Cell-free DNA (cfDNA) mutations from clonal hematopoiesis: Implications for interpretation of liquid biopsy tests. J. Clin. Oncol. 35, 11526-11526 (2017).

30. Genovese, G., S. Jaiswal, B. L. Ebert, S. A. McCarroll. Clonal hematopoiesis and bloodcancer risk inferred from blood DNA sequence. 371, 2477-2487 (2015).

31. Ou, S.-H. I., M. Nagasaka, V. W. Zhu. Liquid biopsy to identify actionable genomic alterations. Am. Soc. Clin. Oncol. Educ. Book 38, 978-997 (2018).

32. Newman, A. M., S. V. Bratman, J. To, J. F. Wynne, N. C. Eclov, L. A. Modlin, C. L. Liu, J. W. Neal, H. A. Wakelee, R. E. Merritt, J. B. Shrager, B. W. Loo Jr., A. A. Alizadeh, M. Diehn. An ultrasensitive method for quantitating circulating tumor DNA with broad patient coverage. Nat. Med. 20, 548-554 (2014).

33. Lanman, R. B., S. A. Mortimer, O. A. Zill, D. Sebisanovic, R. Lopez, S. Blau, E. A. Collisson, S. G. Divers, D. S. Hoon, E. S. Kopetz, J. Lee, P. G. Nikolinakos, A. M. Baca, B. G. Kermani, H. Eltoukhy, A. Talasaz. Analytical and clinical validation of a digital sequencing panel for quantitative, highly accurate evaluation of cell-free circulating tumor DNA. PLoS One 10, e0140712 (2015). 
34. Zang, Y. S., C. Dai, X. Xu, X. Cai, g. Wang, J. Wei, A. Wu, W. Sun, S. Jiao, Q. Xu. Comprehensive analysis of potential immunotherapy genomic biomarkers in 1000 Chinese patients with cancer. Cancer Med. (2019). Doi: 10.1002/cam4.2381.

35. Loman, N. J., R. V. Misra, T. J. Dallman, C. Constantinidou, S. E. Gharbia, J. Wain, M. J. Pallen. Performance comparison of benchtop high-throughput sequencing platforms. Nat. Biotechnol. 30, 434-439 (2012).

36. Chennagiri, N., E. J. White, A. Frieden, E. Lopez, D. S. Lieber, A. Nikiforov, T. Ross, R. Batorsky, s. Hansen, V. Lip, L. J. Luquette, E. Mauceli, D. Margulies, P. M. Milos, N. Napolitano, M. M. Nizzari, T. Yu, J. F. Thompson. Orthogonal NGS for high throughput clinical diagnostics. Sci. Rep. 6, 24650 (2016).

37. Koboldt, D. C., Q. Zhang, D. E. Larson, D. Shen, M. D. McLellan, L. Lin, C. A. Miller, E. R. Mardis, L. Ding, R. K. Wilson. VarScan 2: somatic mutation and copy number alteration discovery in cancer by exome sequencing. Genome Res. 22, 568-576 (2012).

38. Li, H., R. Durbin. Fast and accurate short read alignment with Burrows-Wheeler transform. Bioinformatics. 25, 1754-1760 (2009).

39. Li, H., B. Handsaker, A. Wysoker, T. Fennell, J. Ruan, N. Homer, G. Marth, G. Abecasis, R. Durbin; 1000 Genome Project Data Processing Subgroup. The sequence alignment/map format and SAMtools. Bioinformatics. 25, 2078-2079 (2009).

40. Quinlan, A.R., I. M. Hall. BEDTools: a flexible suite of utilities for comparing genomic features. Bioinformatics. 26, 841-842 (2010).

Acknowledgments: We are very grateful to GenomiCare Biotechnology Co. Ltd., including data analysis by members of the bioinformatics department, testing work by the lab members, clinical data collection and entry by members of the clinical data department, and the collection and collation of patient follow-up information by members of the customer relationship department.

Funding: This study was supported by the major scientific and technological project of Guangdong Province (No. 2017B030308006), the major program for tackling key problems of Guangzhou City, China (No. 201704020144), National Natural Science Foundation of China (NSFC) (No. 81171441), and Science and Technology Program of Guangzhou (No. 201803010073).

Author contributions: Qiang Xu, Yanhong Deng, and Jiaping Li conceptualized and designed the study; Wei Jiang and Jinwang Wei contributed to the experimental design and methodology, and administered the project; Jianwei Zhang, Linbo Cai, Minjie Luo, and Zhan Wang communicated with patients, and collected and organized patient follow-up information; Chen Wang, Wending Sun, and Chun Dai performed the experimental work; Jinwang Wei, Guan 
Wang, and Qiang Xu performed the bioinformatics and statistical analysis; Wending Sun wrote the manuscript. All authors approved the final version of the manuscript.

Competing interests: The authors declare that they have no competing interests.

Data and materials availability: The datasets used and/or analyzed in the study are available from the corresponding author on reasonable request. 